\title{
Sustainability Impacts of Agrarian Governance in Bulgaria
}

\author{
Hrabrin Bachev \\ Institute of Agricultural Economics, Sofia, Bulgaria \\ E-mail: hbachev@yahoo.com
}

\begin{abstract}
This article incorporates the interdisciplinary New Institutional Economics framework, and assesses the impact of diverse market, private, collective, public and hybrid modes of governance on agrarian sustainability at the current stage of development in Bulgaria. First, the system of agrarian governance and its analysis is outlined. After that dominating governing modes in Bulgarian farms of different juridical type, size, specialization, ecological and geographical location are identified, and their impacts on agrarian sustainability and its economic, social, and environmental pillars evaluated. In conclusion implications for further research, public policy improvement, and private managerial strategy formation are presented.
\end{abstract}

Keywords: Agrarian Governance, sustainability, market, private, collective, hybrid modes.

\section{Introduction}

Achievement of diverse economic, social, environment conservation, intergenerational, etc. goals of sustainable development greatly depend on the specific system of governance in different countries, industries, regions, communities, etc. (Furuboth and Richter, 1998; North, 1990; Williamson, 1996). Having in mind the importance of agrarian sector (in terms of employed resources, contribution to individuals and social welfare, positive and/or negative impacts on environment, etc.), the improvement of the governance of agrarian sustainability is among the most topical issues in Bulgaria and around the globe (Bachev, 2010, 2016, 2018; Bachev et al., 2016; EC, 2017; Raman, 2006; Sauvenier et al., 2005; Terziev and Radeva, 2016; UN, 1992, 2015).

Nevertheless, research on forms and efficiency of the governance of agrarian sustainability is at the beginning stage due to the "newness" of the problem, and the emerging new challenges at the current phase of development (environmental pollution and degradation, climate change, competition for natural resources with other sectors, etc.), and the fundamental institutional modernization during recent years, and the "lack" of long-term experiences and relevant data, etc. Most studies in the area are focused on the formal modes and mechanisms while the important informal institutions and organizations are not included into analysis. What is more, research is commonly restricted to a certain form (contract, cooperative, industry initiative, public program), or a management level (farm, eco-system, region, international) without taking into consideration the interdependency, complementarities and/or competition of different governing structures. Besides, widely used complex forms of governance (multilateral, multi-level, reciprocial, interlinked, hybrid) are usually ignored.

Likewise, one-dimensional and uni-sectoral analyses are broadly used separating the management of agricultural activity from the governance of environmental and the overall households and rural activities. Furthermore, most studies concentrate on technology related ("production") costs ignoring significant transaction costs associated with the identification, assignment, protection, exchange and disputing of diverse property rights and rules. Moreover, "normative" (to some "ideal" or "model in other countries") rather than a "comparative institutional approach" (between feasible alternatives in the specific socio-economic and natural conditions of a country, region, sector, ecosystem) is employed. Furthermore, uni-disciplinary approach dominates ("pure economic", "pure ecological", "pure juridical", "pure political", etc.) preventing a proper understanding of the driving factors ("logic") and the full consequences (multiple effects, costs, risks) of a particular governance choice. Consequently, a complete understanding and adequate assessment of the system of agrarian governance and its contribution to agrarian sustainability is impeded, and the effective assistance to public policy and private (individual and collective) strategy formation cannot be given by researchers and experts. 
In Bulgaria, with very few exceptions (Bachev, 2010; Georgiev, 2010), there are no empirical studies on dominating governing structures in agriculture, and their impact(s) on agrarian sustainability. In this paper interdisciplinary New Institutional Economics framework (combining Economics, Organization, Sociology, Law, Political and Behavioural Sciences) is incorporated, and the impact of diverse private, collective, public and hybrid modes of governance on agrarian sustainability at the current stage of development in Bulgaria assessed. First, the methodological framework of the study is outlined. After that dominating governing modes in Bulgarian farms of different juridical type, size, specialization, ecological and geographical location are identified, and their impacts on agrarian sustainability and its economic, social, and environmental pillars evaluated. In conclusion implications for further research, public policy improvement, and private managerial strategy formation are presented.

\section{$2 \quad$ Framework of Analysis}

Maintaining and improving the social, economic and ecological functions of agriculture requires an effective social order (a "good governance") - a system of "human created" mechanisms and forms regulating, coordinating, stimulating, and controlling behaviours, actions and relations of individual agents at different levels (Bachev, 2010). The system of governance of agrarian sustainability is a part of the specific system of "agrarian" governance and includes: diverse agrarian and non-agrarian agents, and a variety of mechanisms and forms for governing of behaviour, activity, relations, and impacts of related agents.

The individual farms are the main organizational and production units in agriculture, which manage resources, technologies and activity, and maintain social, economic and ecological functions of the sector. Thus, farms and farm (production, service, innovation, marketing, etc.) organizations are the major elements of the system of governance of agrarian sustainability (Figure 1). Other agents also directly or "indirectly" participate in the governance of agrarian sustainability imposing appropriate conditions, standards, norms, demands, etc. These are the owners of agrarian (land, material, finance, intellectual, etc.) resources, who are interested in their effective utilization, conservation, and multiplication. Next, that is related business including suppliers of inputs, finance, innovations, buyers of farm produces, etc. They all impose socio-economic and ecological standards, specific support and demand for sustainable agrarian performance. Next, these are final consumers of farm and related produce, residents, visitors of rural areas, and diverse interests groups, which "impose" conditions (pressure, demand) for environmentally friendly, socially responsible, and economically viable agriculture and rural regions. Finally, those are the state and local authorities, international organizations, etc., which assist initiatives for agrarian sustainability of different agents, and/or impose mandatory (social, economic, environmental, animal welfare, etc.) standards for sustainable production, distribution, and consumption.

The system of governance of agrarian sustainability includes a number of distinct ("generic") mechanisms and modes, which manage behaviour and actions of individual agents, and eventually (pre)determine the level of agrarian sustainability (Figure 1): First, institutional environment ("rules of the game") - that is the distribution of rights and obligations between individuals, groups, and generations, and the system(s) of enforcement of these rights and rules (Furuboth and Richter, 1998; North, 1990). Second, market modes ("invisible hand of market") - those are various decentralized initiatives governed by the "free" market price movements and market competition - e.g. spotlight exchange of resources, products and services; "classical" purchase contract, lease or sell contract; trade with high quality, organic, etc. products and specific origins, agrarian and ecosystem services, etc. Third, private modes ("private or collective order") - diverse private initiatives, and special contractual and organizational arrangements (long-term supply and marketing contracts, voluntary eco- and social actions, voluntary or obligatory codes of behaviour, partnerships, cooperatives and associations, brads and trademarks, labels, etc.). Forth, public modes ("public order") - various forms of public (community, government, international) interventions in market and private sector such as public guidance, regulation, assistance, taxation, funding, provision, property right modernization, etc. Fifth, hybrid forms - some combination of the above three modes like public-private partnership, public licensing and inspection of private organic farms, etc. 


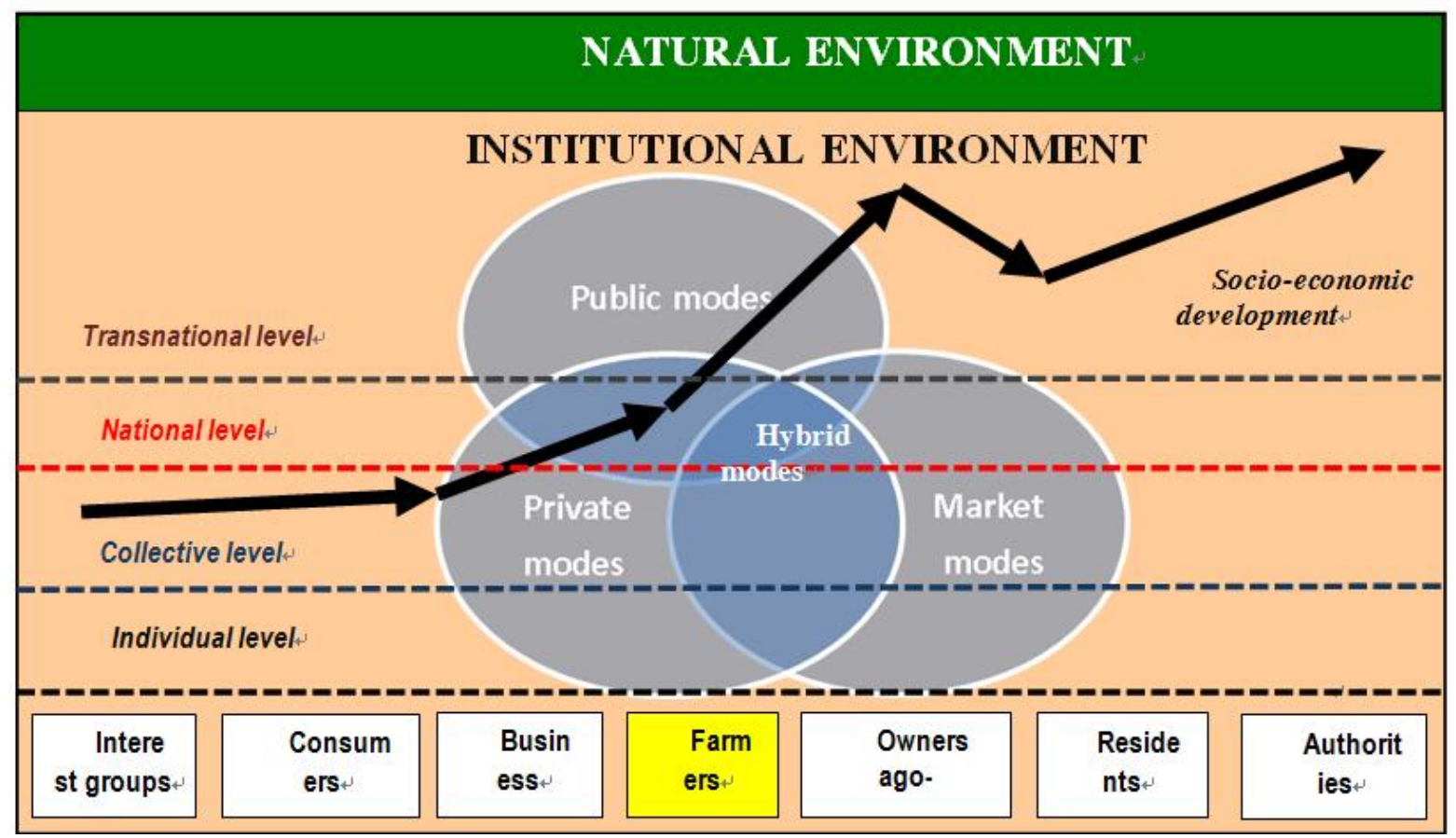

Source: author

Figure 1. System of governance of agrarian sustainability

In a long run the specific system of governance of agrarian sector and sustainability (pre)determines the type and character of social and economic development. Depending on the efficiency of the specific system of governance of agrarian sustainability "put in place", individual farms, subsectors, regions and societies achieve quite dissimilar results in socio-economic development and environmental protection, and there are diverse levels and challenges in economic, social and ecological sustainability of farms, subsectors, regions, etc. (Bachev, 2010).

Efficiency of the specific system of governance of agrarian sustainability eventually finds expression in certain level and dynamics of the social, economic, ecological and integral sustainability of agriculture as whole or agricultural systems of different type (farm, industry, agro-ecosystem, region, etc.). Accordingly, a high or increasing agrarian sustainability means a high efficiency of the system of governance, and vice versa. Agrarian sustainability is defined in a number of ways and still there is no agreement about what agrarian sustainability is and how to evaluate its level (Raman, 2006; Sauvenier et al., 2005). In this paper sustainability is understood as a "system characteristic" and the ability of agriculture to maintain its economic, ecological and social functions over a long period of time. Agrarian sustainability and its individual aspects have multiple dimensions. In order to assess the efficiency of the governance a holistic system for assessing the social, economic, ecological and integral sustainability is applied, presented in other publications (Bachev, 2016; Bachev et al., 2016).

For identification and assessment of diverse market, private, collective, hybrid, etc. modes of governance and its impact on agrarian sustainability in Bulgarian agriculture, its major subsectors, in various geographical and ecological regions, as well as sustainability contribution of farms of different juridical type and size, in-depth interviews were carried out in 2017 with the managers of 40 "representative" market-oriented farms of different kind and location. The survey comprises multiple questions associated with the usage and the impact of diverse components of governing system (personal preferences, resource endowment, specific managerial strategies, applied contractual and collective forms, participation in public support schemes, community and counterparts initiatives and pressure, etc.) on agrarian sustainability, and its social, economic and environmental aspects. Initially the managers assessed the impact of each particular governing mode as "positive", "neutral", or "negative". After that, the relations between the "estimates" of the managers for the efficiency of governing modes, and the sustainability level of respective farms are specified. The integral estimates are arithmetic averages of the assessments of individual farms of a particular type. 
The assessment is based on first-hand data collected from the managers of "typical" farms of different type and location. That approach is only feasible since there are no available "objective" statistical, monitoring, survey, etc. information about the employed (preferred, failed) governing modes, and the impact of a particular element of the governing system on agrarian sustainability. Besides, the farm managers are the most aware with the "efficiency" of dominating governance mechanisms and modes, and its relation (timing, direction, and extent of the effect) to agrarian sustainability in the specific conditions of their own farm, region, subsector, etc. Besides, when there is available aggregate data for certain mode(s) of governance (e.g. particular type of contract, public regulation or support schemes, etc.) there is no way to know how they contribute to sustainability since "rational" agents adapt modes maximizing their efficiency (minimizing private costs, maximizing private benefits) which may or often fail to maintain/improve the overall efficiency and sustainability (Bachev, 2010). Furthermore, for certain data the farm managers are the sole or only reliable source of information - e.g. personal ideology, preferences, and satisfaction, interlinked and complex forms, widespread informal modes, level of sensibility and adaptation to outside pressure and demand, etc. Nevertheless, in order to diminish subjectivity, the assessments ("perceptions") of the managers are complemented with the "objective" assessment of sustainability level of their farms, and the correlation determined between the managers' estimates on the importance of a particular governing mode and the actual sustainability level.

\section{$3 \quad$ Assessment of Individual Governing Modes}

Our surveyed has found out that, for all managers their "own personal conviction and initiatives" are important positive factor for maintaining and improving agrarian sustainability and its dimensions (Figure 2). Understandings, skills, and targeted actions of the agrarian entrepreneurs and managers of farms of all juridical types, sizes, production specialization, ecological and geographical locations, are a key factor for accomplishing socio-economic and environmental aspects of agrarian sustainability.

At the same time, merely a quarter of the managers indicates, that the "personal conviction and initiatives of workers" is a positive factor for agrarian sustainability (Figure 2). The latter is important for innovating enterprises of different type, which rely on and create conditions for involvement of all workers in improvement of farm activity and agrarian sustainability - selection of qualified stuff, continuing training, freedom to apply and experiment initiatives, delegation of management and responsibilities, strong incentives, output based compensation, etc. However, for the biggest part of Bulgarian farms the hired labour does not have needed quality, freedom, and/or motivation and contribute little to amelioration of agrarian sustainability.

Available and accessible resources and innovations are essential factors for effective and sustainable development. According to three quarters of the managers of surveyed holdings existing "resource and innovation potential of the farm" contribute positively to agrarian sustainability and its individual aspects (Figure 2). The majority of farmers appreciate highly the significance of that factor and believe that their holding possesses necessary human, land, material and intellectual resources for achieving socio-economic and environmental goals of agrarian sustainability. Commonly, the control on "critical" for the farm resources are secured through internal governance (acquiring ownership, permanent labour contract, etc.) or external collective or leading organization (cooperative, association, holding, etc.). More "mobile" resources are governed through long-term lease contracts, while for the "universal" assets and products it is relied on market modes.

Nevertheless, $15 \%$ of the surveyed farms assess as negative the effect of their insufficient resource and innovation potential for the needs of sustainable development. Many farms with a smaller size, with lower public support, and poor regions of the country do not have sufficient own resources and innovations, neither access to external sources for effective and sustainable operations. On the other hand, every tenth manager does not suggest that existing resource and innovation potential of the farm is important for agrarian sustainability and some of its aspects. For that portion of the farmers, for the accomplishment of socio-economic and environmental sustainability are more important personal conviction, skills and strategies of the farmers, public stimulation, regulation and support policies, etc., rather than currently available resources.

The farms of different type and sizes, subsectors and locations are with unequal potential of own and external resources and innovations for successful implementation of sustainable development strategies. 
The greatest share of holdings with existing resources and innovation potential for sustainable development are among Sole Traders (87,5\%) and Companies (81,82\%), farms with Middle (85,71\%) and Big (100\%) sizes, holdings specialized in Grazing livestock (100\%), Mix livestock (100\%), and Permanent crops (90\%), and located in Plain regions $(81,25 \%)$ and Less-favored non-mountainous regions $(100 \%)$ as well as in South-East $(85,71 \%)$ and North-Central $(80 \%)$ regions of the country.

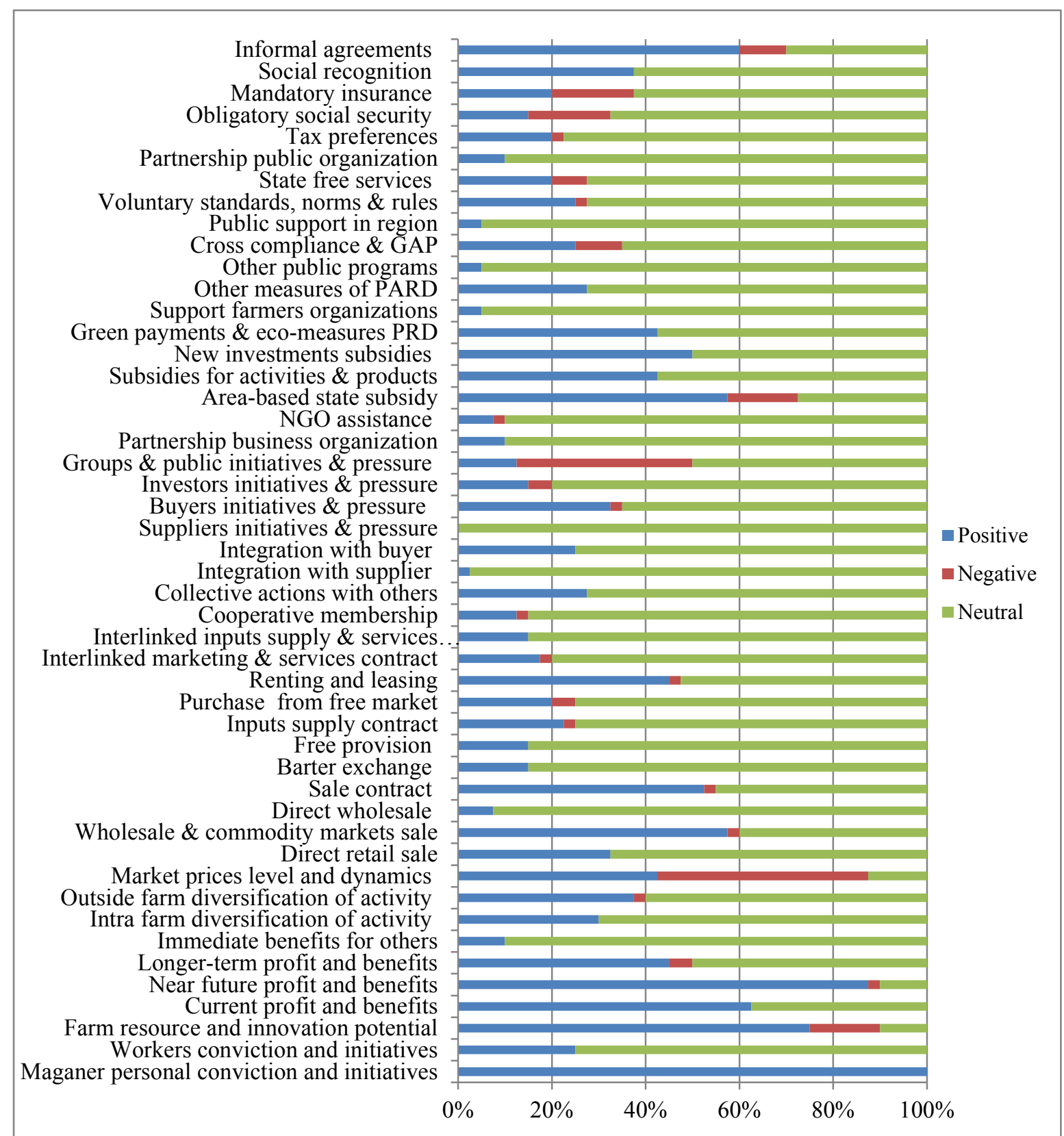

Source: interviews with managers of farms, 2017

Figure 2. Impact of private, collective and hybrid factors, forms and strategies on agrarian sustainability in Bulgaria (percent)

The smallest number of farms with effective resource and innovation potential for sustainable development are among Cooperatives (50\%), holdings Predominately for subsistence (33,33\%) and Small size $(60 \%)$, and producers specialized in Pigs, Poultries and Rabbits (50\%), Field crops and Mix crops 
(by 60\%), as well as farms located in Mountainous regions (66,67\%), with Lands in protected zones and territories (60\%), and in South-Central region of the country $(70,59 \%)$.

Strategies with a different time horizon to a different extent contribute for maintaining and achieving agrarian sustainability. For instance, realization of some economic objectives and most environmental and social goals of sustainable development often requires continuous long-term efforts and investments from participating agents. According to the majority of surveyed managers $(60 \%)$ "current profit and benefits" are a substantial factor, which affect positively the governance of agrarian sustainability and its main aspects (Figure 2). Simultaneously, the rest significant part of the managers $(37,5 \%)$ evaluate the importance of that type of strategy as neutral in relation to agrarian sustainability and its individual dimensions. The latter know that orientation of activity and efforts solely to present profit and benefits little contribute to agrarian sustainability and its aspects.

The best fraction of surveyed farms $(87,5 \%)$ believes that "profit and benefits in near future" are important factors favourable for sustainable agriculture (Figure 2). The majority of managers are convinced that realization of the diverse socio-economic and environmental goals of agrarian sustainability requires longer-term efforts, and therefore undertake such managerial strategies. Only a tiny portion of questioned $(2,5 \%)$ evaluate that orientation toward near future profit and benefits is negative in relation to agrarian sustainability and its aspects. Besides, every tenth manager thinks that undertaking a "short-term" strategy aimed merely at profit and benefits in near future is a neutral factor not contributing significantly to agrarian sustainability and its socio-economic and environmental aspects.

A relatively smaller segment of the Bulgarian farms applies strategies oriented to profit and benefits in a long-term (which are actually the means for achieving and maintaining agrarian sustainability). One considerable part of all surveyed managers (45\%) assess as positive for agrarian sustainability and its main aspects directing the farm activity toward "profit and benefits in a longer-term" (Figure 2). Only a small portion of holdings (5\%) suggests that such strategy for profiting and benefiting in a longer-term is negative for agrarian sustainability. At the same time, every another farm evaluates as neutral in relation to agrarian sustainability and its aspects the strategy for profit and benefits in a longer-term.

All these demonstrate that the best part of the Bulgarian farms does not direct their activities for achieving the long-term goals of socio-economic development of the sector, but toward specific goals in shorter time horizons. Many holdings are forced to direct their efforts toward immediate benefits in current period or in near future because of the necessity for "economic survival" in the conditions of intensive competition. Numerous farms are less interested in or able for long-term investments for improving its economic viability, social responsibility, and environmental stewardship. According to many interviewed presidents of Cooperatives "the young generation does not care for the future" and future development of the cooperative farms is associated with a great uncertainty. It is well-known that similar type of (short-term) private farming strategies does not correspond to (long-term) governance needs of sustainable development. That further necessitates the intervention of a "third party "(the state, local authority, private, non-governmental and international organizations, etc.) for effective achievement of agrarian sustainability.

Effective contribution of the various types of farms through long-term strategies for agrarian sustainability is quite different. In the greatest extent strategies directed to longer-term profit and benefits are applied by the firms of different type - Companies (63,64\%) and Sole Traders (62,5\%) as well as holdings with Big sizes (62,5\%). All these farms have greater financial and overall capabilities for long-term investments for agrarian sustainability, stronger incentives (goal) for development of the firm, and evaluate as positive the orientation of efforts toward long-term benefits. On the other hand, relatively smaller parts of the Cooperative farms (16,67\%), Physical Persons (33,33\%), holdings with Small size $(26,67 \%)$ and Predominately for subsistence $(33,33 \%)$ employ strategies for long-term profit and benefits. The latter is caused by the lack of funding, strive to survival in the conditions of low efficiency and high competition as well as the typical for these kind of farms short investment horizon due to the advance age of farmers, lack of successor ready to take up the farm, impossibility to trade unregistered farms or cooperative shares, low rent and lack of dividend for cooperative shares, etc.

Toward long-term profit and benefits orient their strategies most of the farms specialized in Permanent crops (80\%), Mix livestock (100\%), and Grazing livestock (66,67\%). Those are predominately productions, requiring long-term investments and commonly "paying back" in longer periods of time. On 
the other hand, in productions with a rapid return on investments the long-term profit and benefits are to a lesser extent a factor for the strategy formation. Neither of producers in the Field crops and Pigs, Poultries and Rabbits assesses as positive such a strategy, while in the Vegetables, Flowers and Mushrooms only a quarter of them. Obviously, these types of strategies little contribute to improvement of the social and environmental aspects of agrarian sustainability.

Similarly, in the regions with natural handicaps a relatively larger share of the managers assesses as positive the strategy oriented towards long-term profit and benefits - accordingly $75 \%$ in Less-favoured non-mountainous regions and 57,14\% in Less-favoured mountainous regions. At the same time, in Plainmountainous regions solely a third of the agricultural producers apply long-term strategies for agrarian sustainability. In different geographical regions approximately similar portions of the farms (around 40$43 \%$ ) implement long-term strategies for governing of agrarian sustainability. Only holdings in Southwest region are exceptions where favourable effects of long-term strategies for diverse aspects of agrarian sustainability are appreciated to a greater extent $(58,92 \%)$.

Received benefits from other persons and groups from the farm activity are important (social and environmental) aspects of agrarian sustainability. Our survey has found out that, merely for $10 \%$ of interviewed managers the "immediate benefits for other persons and groups" are a positive factor for directing of activity (Figure 2). Such objectives are predominately important for the agricultural cooperatives, for which in addition to the members and workers, benefits are particularly of significance (or at least so declared) for farm households and rural communities as well. However, for a remaining greater portion of the farms the immediate benefits for other persons and groups, are not parts of strategies and has no importance (neutrality) in relation to agrarian sustainability.

Diversification of activity is an important strategy for amelioration of socio-economic and environmental sustainability in agriculture. That mode of management of agrarian sustainability is widely practiced by the Bulgarian farmers as well. According to $30 \%$ of questioned managers they implement a strategy for "diversification of activity in the farm" affecting positively the agrarian sustainability and its aspects (Figure 2). Many farms produce several products and services for better utilization of available land and other resources, application of effective agro-technics (crop rotation) and protection of natural environment, reduction of risk from climate and market prices variation, using free machinery (providing mechanization and other services), etc. At the same time, none of the holdings considers as negative for the agrarian sustainability the diversification of activity within the farm boundaries.

Nevertheless, most of the surveyed farms employ another more effective strategy - for specialization of activity in one or more products. For $70 \%$ of the managers the diversification of activity in the farm has no effect (neutral) on agrarian sustainability and its different aspects. A greater specialization allows exploration of economies of sizes and scopes, increasing productivity, investing in specialized skills and technologies, more efficient marketing (selling a single product in large volumes, negotiation of better prices, reputation building, establishing supply chain networks, etc.).

Many examples have been found among surveyed farmers of "experimenting" in production diversification in search for higher benefits, and depending on the outcome it is either given up or entered in the new productions. For instance, a strawberry producer invested in a large-scale potato production, while a livestock farmer experimented in open vegetable operation, but after realized losses both producers abandoned diversification strategy. Similarly, a cooperative and a farm tried with rapeseed or field vegetables (the latter quit due to a lack of profitability), another farmer is experimenting on the part of lands with organic production to test the efficiency and take advantage of provided public subsidies, etc. Many cooperatives sell yields immediately after harvesting and lose from not-waiting the best prices. Here diversification into grain storage is unbeneficial both temporary storing at farm (destructions by birds, rodents, bad weather, etc.) as well as long-term renting of external warehouses (a high price of 1 stotinka per $\mathrm{kg}$ ).

Farms of different type, production specialization and location, to a various extent take advantage of the favourable effect of the diversification within the farm. To a greatest extent the diversification in the farm is employed and appreciated as positive for agrarian sustainability by the Companies $(36,33 \%)$ and every third of the Cooperatives and Physical Persons. At the same time, most of the Sole Traders widely practice product specialization, and only $12,5 \%$ of them suggest that diversification in the farm is a positive factor for agrarian sustainability. 
Our survey has also found out that to a greatest extent the diversification of activity within the farm is applied by the holdings with a Big for the sector size (62,5\%). That type of farms possesses bigger capability for seeking benefits in many directions, incentives for distribution of risk, and agrotechnological necessity for certain diversification for effective utilization of resources (land, labour, machinery) and environmentally friendly agriculture (needs for crop rotation). On the other hand, smaller farms to a lesser extent appreciate as positive the implementation of strategies for intra-farm diversification - only a fifth of holdings with Small sizes and 21,43\% of those with Middle sizes. Every third holding Predominately for subsistence diversifies its activity in the farm for a greater satisfaction of its diverse needs of agricultural products and better utilization of family resources.

To the greatest extent diversification within the borders of the farm is implemented by holdings specialized in Mix livestock (all of them), and Mix crop-livestock orientation (60\%). Simultaneously, none of the farms in highly specialized production like Vegetables, Flowers and Mushrooms, and in Pigs, Poultries and Rabbits applies product specialization in the farm. Relatively to a lesser extent that strategy is employed in the sectors Field crops and Mix crops - merely 20\% of holding. A greater share of the farms, located in Mountainous regions $(44,44 \%)$, in Less-favoured non-mountainous regions (every other one), and with Lands in protected zones and territories (40\%) implement diversification within the farm for improving agrarian sustainability. Most part of farms in Plain regions (three quarters) and Plain-mountainous regions $(73,33 \%)$ as well as in Less-favoured mountainous regions $(71,43 \%)$ do not believe that diversification of activity in the farm is an effective strategy for enhancing agrarian sustainability. All these farms aim at specialization in particular product/s for increasing productivity of limited agrarian resources in such regions. To the greatest extent are diversified farms in South-East region of the country $(57,14 \%)$, while none of the holdings in the North-Central region assess as positive that type of strategy in relation to agrarian sustainability.

Diversification of activity outside of the farm is another feasible strategy for improving efficiency and elevating agrarian sustainability. It gives possibility for specialization in the farm for achieving maximum productivity (efficiency) of agrarian resources, while simultaneously it is looked for new opportunities in related to agriculture (such as processing, marketing, supply of services, agro-tourism, restaurant, eco-system services, etc.) and/or unrelated activities (other industries, services) for assuring employment, additional income, profit, risk sharing, etc. outside the farm gates. A good portion of interviewed managers $(37,5 \%)$ practice a strategy for diversification of activity outside the farm and evaluate its impact on agrarian sustainability as positive (Figure 2). A good fraction of holdings diversifies into farm produce processing (vine, dairy, etc.) or marketing (own shops, labels, trademarks, etc.), while others point out a great variety of other activities (inputs and technology supply for green houses, hotel and hospitality, transportation, mountain tourism, etc.).

Our study has also found out that many individuals and households, having another major (nonagrarian) business or temporary available resources (free time, unemployment, students, own farmland, etc.) "diversify" into farming activity in order to increase family incomes or utilize free resources. Those are mainly younger entrepreneurs with a successful (or developing) family business in other sectors of the economy (hotel, fitness club, mountain tourism, etc.) who invested in agrarian sphere (production of snails, strawberries, etc.). Some of them get involved in the activity and/or management of existing family farms (of parents, relatives) in order to take advantage of different forms of public support such as assistance to young farmers, etc. A manager of a modern vegetable greenhouse has been also interviewed, who "unwillingly" entered agrarian business. He has another main business in consulting, crediting, and import of modern greenhouse technologies (hydroponics, precision agriculture, etc.), crop varieties, and chemicals from Netherlands. In recent years, many of his clients-farmers have been experiencing serious economic difficulties, and unable to return provided by him (interlinked with inputs and innovation supply) credits, and failed down. In order to "save" one already well developed greenhouse and apply his good knowledge in that area, the entrepreneur exchanged the previous owner's debt for taking-over the greenhouse business.

The majority of surveyed farms (60\%) are exclusively specialized in agricultural activities, they do not practice diversification outside the farms, and assess as neutral the impact of that factor on agrarian sustainability or some of its aspects. A small fraction of the managers $(2,5 \%)$ even think, that diversification of activity outside the farm is a negative factor for agrarian sustainability or for its economic, social or environmental aspect(s). 
To a greatest extent the extra farm diversification is implemented by the firms of different type - Sole Traders $(62,5 \%)$ and Companies $(63,64 \%)$. Those are business oriented forms, in which entrepreneurs have resources and constantly search for profit opportunities in the agrarian sector and elsewhere. Contrary, a relatively smaller segment of the Physical Persons (13,33\%) and Cooperatives (16,67\%) practice diversification outside farm gates and believe that such a strategy is favourable for agrarian sustainability. Similarly, a half of the Big farms see diversification outside the farm as a vehicle to increase agrarian sustainability or some (mostly economic) aspects. On the other hand, Middle size holdings implement to the weakest extent extra farm diversification (21,43\%).

Agricultural producers specialized in different subsectors unequally apply diversification outside the farm-gates. No holding, specialized in Field crops, Grazing livestock, and Mix livestock practices such a strategy or evaluates it as favourable for augmenting agrarian sustainability. At the same time, all farms specialized in Pigs, Poultries and Rabbits, as well as a good part of those in Vegetables, Flowers and Mushrooms (75\%) and Permanent crops (70\%) applies strategies for diversification of activity outside of the farm. The latter are usually subsectors with significant economic problems (pig production, vegetable production, etc.) or production closely integrated with the processing (grape and milk production, etc.).

Holdings in Plain (43,75\%) and Plain-mountainous (40\%) regions to a greater extent use diversification outside the farm, comparing to the farms in Mountainous regions (22,22\%). Farms located in Less-favoured mountainous regions $(42,86 \%)$ and with Lands in protected zones and territories (40\%) practice more broadly a strategy for outside farm diversification, comparing to the holdings in Less-favoured non-mountainous regions (25\%). The biggest share of the managers assesses as positive for agrarian sustainability the outside farm in diversification of activity the South-Central region $(47,06 \%)$, while to a smallest degree such diversification is practiced by the farms in the NorthCentral region (one fifth of them). All above is a consequence of the existing practical possibilities for diversification of the business (consumers demand, available resources, entrepreneurial skills, free time, etc.) as well as the real needs and perceptions of agricultural producers in referred regions.

Market prices and competition are an important mechanism for governing of activity of various agents (resource owners, entrepreneurs, farmers, consumers, etc.). According to a significant part of the interviewed managers (42,5\%) "the level and dynamics of market prices" have a positive impact on (manages, coordinates, stimulates) their activity and agrarian sustainability (Figure 2). The favourable effect of market mechanisms is appreciated to a various degree by different type of farms and producers in diverse subsectors and regions taking advantage of their comparative advantages and competitiveness and profiting from price levels and dynamics. At the same time, a good portion of holdings (12,5\%) think that the market prices level and dynamics do not affect agrarian sustainability and some of its aspects. Some small and situated in remote areas producers do not "feel" real market prices and their dynamics (undeveloped or missing markets). For another part of the managers the achievement of agrarian sustainability requires a loner-term strategy (management), rather than governance based on the fluctuation of („current”) market prices. What is more, certain "products” of the farm have a public good character (conservation of tradition, natural environment, biodiversity, etc.) for which there are no markets and prices at all.

For the biggest part of surveyed farms (45\%) the level and dynamics of market prices at the present stage of development impact negatively agrarian sustainability and its individual aspects. The majority of managers underline the negative effect of the market as a dominant mechanism for maintaining (and achieving) economic, social, and environmental goals of agrarian sustainability. Most often it is pointed out that market prices are too low for effective (profitable) operations and sustainable agriculture. It is also emphasized that price fluctuations are great and unpredictable, and obstruct the governance of agrarian sustainability requiring long-term (permanent) investments in productive, socially responsible and environment preservation production. Moreover, the lack of any prices and markets for some of the socially important (public, quasi-public, collective, quasi-private, etc.) products and services of the farms (like conservation, improvement and restoration of natural resources and ecosystems) fail to induce sufficient incentives for effective actions in such directions.

The negative impact of the market prices level and dynamics on agrarian sustainability to a greatest extent affects Sole Traders (62,5\%) and Physical Persons (46,67\%), farms with Small and Middle sizes (60\% and 42,86\% accordingly), holdings specialized in Vegetables, Flowers, and Mushrooms (75\%), Grazing livestock (66,67\%), and Mix livestock (100\%), farms located in Mountainous regions $(66,67 \%)$ 
and with Lands in protected zones and territories (80\%), as well as in North-Central region of the country $(60 \%)$. To the smallest extent the market prices level and dynamics negatively impact the Cooperatives (one third) and Companies (36,36\%), Big farms (a quarter) and holdings Predominately for subsistence (every third), producers specialized in Field crops (every fifth) and Permanent crops $(30 \%)$, farms located in Plain regions $(3,25 \%)$ and in Less-favourite non-mountainous regions $(25 \%)$, as well as in South-Central region of the country $(41,18 \%)$.

Effective realization (marketing) of farm products and services is an essential factor for agrarian sustainability and for economically viable, socially stable, and environmentally friendly agriculture. In order to benefit from market opportunities and safeguard against market risks (low prices, price fluctuations, contractual asymmetry, likely opportunism, delayed payment, etc.) agricultural producers use and/or develop diverse effective forms of marketing of farm produce.

"Direct retail sale of products and services" is practiced as an effective form of marketing by $32,5 \%$ of surveyed farms (Figure 2). Those are holdings with different sizes, specialization, and location, for which direct sales are highly efficient due to superior "retail" prices, low costs for direct marketing (on farm or local farm market), low risk for opportunism, etc. Usually, those are producers with smaller sizes, having small volume of production and sales, loyal clients in the region and/or good location (proximity to highway, resort, large consumer centre), seasonable and high quality products with a big demand (fresh fruits and vegetables, lamb meat, eco-products). In some cases, agricultural produce is sold "in package" with another service and it is profited from the interlinked retail marketing - e.g. self-pick up of farm produce by client, serving of produced fresh or processed produces in own restaurant, etc.). Many of the biggest vertically integrated agricultural producers (vine growing and wine producing complexes and vineries, dairy and meat processors with own livestock, etc.) possess own brand shops for direct retail sale of final products in the region and/or big cities.

None of the surveyed managers believes that such mode of marketing affects negatively agrarian sustainability. Simultaneously, for the majority of Bulgarian farms $(67,5 \%)$ direct retail sale output does not have significant importance for the governance of agrarian sustainability or some of its aspects. The greatest portion of the Bulgarian farms uses other (more efficient) forms for realization of farm produce. Most of the surveyed farms (57,5\%) widely practice "direct wholesale" of output and evaluate its impact as positive on agrarian sustainability (Figure 2). Those are bigger producers of different type having sufficient volumes and product standardization. The sale commonly is negotiated and implemented directly on farm (field) as most frequent buyers are large processors, retail chains, middlemen, exporters, etc. A considerable fraction of all farms in the country $(40 \%)$ does not apply direct wholesale or do not believe that mode is having a significant importance for agrarian sustainability and some of its aspects. On the other hand, only a tiny fraction of the agricultural producers think that the direct wholesale marketing is not an effective form, mostly for the economic sustainability of agriculture due to lower prices and profit.

The "sale on wholesale and commodity markets" is not a popular form for realization of produced output in Bulgarian farms. For the great majority of surveyed farms (92,5\%) that mode is not essential for agrarian sustainability and its all aspects (Figure 2). Simultaneously, for a small proportion of holdings $(7,5 \%)$ possibility to trade on wholesale and commodity markets is a positive factor in the governance of agrarian sustainability. The latter considers predominately the economic aspect of sustainability for which "discovery" of actual (competitive) market prices through sale on official wholesale or commodity market is a crucial factor for maximum marketing efficiency.

The "sale contract for products and services" is another major mode for governing of marketing of farm produce. According to more than a half of the surveyed managers $(52,5 \%)$ they often use a sale contract and it affects positively agrarian sustainability (Figure 2). Farms commonly deal with several buyers for securing a successful marketing and maximizing revenues. The contract for purchase, sale, or marketing is an important means for planning of realization of output and sale prices. That form is applied by commercial farms of different type, product specialization and location as primary a one year or a yield contact are used. A short-term contract form usually is a policy and requirement of big buyers (processors, food-chains, middlemen, exporters) or preferred by farmers. Very often farmers wish to preserve freedom in order to be able to change a buyer during the next season in case of unsatisfactory (low) prices, delayed payment for product, lack of complementary (crediting, interlinked services, etc.) benefits, change in structure of activity, emergence of a favourable new partner and/or more-effective marketing channel, etc. 
Only a tiny segment of holdings $(2,5 \%)$ assess as positive in regard to agrarian sustainability utilization of the sale contract for product and services. That is mostly in the cases, when farmers face a small number of gig buyers (situation of quasi or full monopoly) imposing unfavourable contract prices, conditions and/or not complying with negotiated terms and compensating affected farms. Frequently smaller producers are not able to comply with requirements of the buyers for certain volumes, timing and regularity of supply, produce quality, variety structure, etc. In other cases, the contract does not include payment for unsold by the retailer products which is returned to the farmer (fresh vegetables and fruits) additionally diminishing the profit for agricultural producers. A good part of the Bulgarian holdings $(45 \%)$ does not employ the contact form for output realization and consider that mode as important for agrarian sustainability or its individual dimensions.

The majority of surveyed farms (85\%) does not practice barter "exchange of products and services for other products and services" and think that governance mode has a significant importance in relation to agrarian sustainability (Figure 2). Similarly, for none of the holdings, such natural exchanges represent a negative factor for agrarian sustainability and some of its aspects. A small portion of the farms believe that product and service exchanges for other products and services have a positive impact on agrarian sustainability. Those are mainly farms with smaller sizes in depopulated and remote from residential places areas. In the condition of imperfect or missing markets for products and services, low incomes (cash) of farmers and rural households, lack of alternative employment or advance age of occupied persons, domination of monopolies etc., some farmers exchange (instead of trading) a portion of produce in mutual benefit and subsequently improve the overall economic, social and/or environmental sustainability of agriculture in the region.

The majority of interviewed managers (85\%) do not use "free provision of resources, products, services and activities" and think they are important in regard to agrarian sustainability (Figure 2). Nevertheless, none of the holdings assess as negative the free provision of resources, products, services and activities from or to others. For a relatively small portion of the farms (15\%) the free provision of resources, products, services and activities is a positive factor for amelioration of agrarian sustainability. Some of the smaller size producers receive free services from other agents and organizations (farmers, cooperatives, non-governmental and international organizations, state and local agencies). Such assistance improves efficiency of the "beneficiaries" and increase agrarian sustainability in the region or subsector. However, often the "free" provision of certain goods and/or services between agrarian (and other) agents comes with an expectation of other or future "reciprocial" free products and/or services.

Some farmers report for informal "free "leasing-out of critical resources such as farmland, buildings etc. as a single form for keeping the land and other assets in a good condition of absent from the region (country) or old of age owners. Also examples are given for "free lease" of agricultural lands in exchange of giving up rights for area based, etc. subsidies from using farmers. The latter is illegitimate form for receiving mutual benefits from the landlords and farmers, which nonetheless maintain agrarian sustainability and do not adversely affect the taxpayers.

The effective governance of farms supplies with needed resources, materials etc. is an important factor for agrarian sustainability. According to the three-quarters of surveyed managers their holdings do not use special "contracts for supply of needed resources" and such a form has no importance regarding agrarian sustainability (Figure 2). Usually markets for supply with major inputs and resources in agriculture "work" well (strong competition, multiple suppliers, etc.) and it is not necessary to apply special modes of governance (guarantee) of supplies. Moreover, farmers are not big users of "external" resources and it is not necessary to develop special (contractual) forms for governing of standard supplies as commonly free markets are used when procurement needs arise. What is more, often longterm relations evolving (high frequency of deals between the farmer and the supplier), and counterparts get to know each other, and are interested in restriction of opportunistic behaviour (the bad reputation is punished easily through changing the supplier).

Only a small fraction of the holdings $(2,5 \%)$ estimates as negative the existence of a contract for supply of required inputs in mind of unfavourable prices or terms of contracts (singe of a small number of supplier). A good portion of the managers (22,5\%) think that employment of a contractual form for supply of needed resources is a positive factor for agrarian sustainability. The contractual mode is preferred in case of greater and frequent supplies of required by the farm resources. The special contract gives possibility to tailor the conditions of exchange and supplies for the needs of a particular farm, as well as to guarantee stable relations between counterparts, and possibility to protect (dispute) the rights 
through the formal (court) system. Some big producers point out examples for supply of special varieties (grape, wheat, etc.) from abroad - France and other leading countries. However, often the existence of quasi or full monopoly (in forage, electricity, water, essential materials etc. supply) leads to serious damages for farmers despite the presence of a contract. In such cases it is impossible to effectively punish a supplier through switching to another supplier and/or enforcement of contract (getting compensation of damages) through a lawful way.

"Purchasing of needed resources and services from free market" is a positive factor for agrarian sustainability and is practiced by one fifth of the surveyed farms (Figure 2). Those are holdings of different type for which market governance of procurement of necessary resources and service is the most efficient. At the same time, for a fraction of farms (5\%) regular purchase of resources and serviced from the "free" market is a negative factor for agrarian sustainability. The latter is consequence of already mentioned cases of occasional or small number of suppliers for certain farms, subsectors and/or regions of the country. The best part of the managers (75\%) believes that supplying of necessary resources and serviced though a purchase from free market is a neutral mode of governance in regards to agrarian sustainability. That implies competitive (well working) markets for supply of standardized products, which are not associated with any special benefits or disadvantages for using farmers.

The lease is a widely used and efficient form for governing of supply of land and other long-term assets in agriculture. That mode allows a rapid and cheap expansion of farm size for better exploration of possibilities for economies of scale and scope, implementation of ecological and other projects, etc. According to a big portion of the surveyed managers (45\%) "renting (leasing) of needed resources" is an effective form and it affects positively agrarian sustainability and its main aspects (Figure 2). The main part of the biggest holdings in the country is also large tenants from numerous small land owners as lease is a major form for expansion of farms sizes in last decades. Usually, a long-term lease is practiced when highly specific investments are made in permanent crops, long-term improvements of land, construction of buildings and equipment, etc. Most frequently the lease is an additional form for governing of the land supply as an acquisition of ownership is preferred by the big investors, particularly when investments are highly specific to a land (vines, orchards, buildings and facilities, etc.) or related productions (wine production, dairy processing). In many cases however, a short-term (a year or season) rent is applied, when there is a desire to experiment in new productions, in greenhouse operations, and monoculture with annual crops (both requiring a periodical change of land plots) or due to unwillingness of landlords for long-term contracts and/or cooperative memberships (facile change of tenant if market demand for farmland is high).

At the same time, more than a half of the holdings in the country (52,5\%) does not rent or lease-in lands or other resources or believe that form is important for agrarian sustainability and some of its dimensions. Only a small fraction of farmers (2,5\%) suggest that renting and leasing of needed resources impact negatively agrarian sustainability. Most often respondents have in mind environmental and social aspects of sustainability. Widespread utilization of large land plots for constant monoculture (lack of crop rotation) in past years has adverse effects on soil preservation (exhaustion, erosion), landscape and biodiversity. What is more, concentration of lands in a small number of large and highly mechanized farms is associated with extermination of the smaller size family holdings and diminution of employment affecting negatively social sustainability of agrarian sector.

To a greatest extent the positive impact on agrarian sustainability from renting and leasing of needed resources is reported by the Cooperatives (83,33\%), and farms with Middle $(57,14 \%)$ and Big (75\%) sizes. Namely the latter to the greatest extent practice leasing and borrowing (mostly farmlands) and apply that specific mode for increasing sustainability of agricultural production. Employment of lease and rent of resources is most favourably reported by farms specialized in Field crops (60\%), Grazing livestock (66,67\%), and Mix livestock (100\%). Simultaneously, resource lease and rent has greater importance for holdings in Plain $(56,25 \%)$ and Plain-mountainous $(46,67 \%)$ regions, in farms with Lands in protected zones and territories $(60 \%)$, as well as located in the South-East region of the country $(71,43 \%)$. For the best part of all other categories of farms and regions that specific mode for extension of farm sizes and governance of agrarian sustainability is less significant or assessed as neutral.

Sometimes in agriculture are also applied more-complex forms for governing of relations between market agents like interlinking the contracts for inputs supply and/or marketing of farm produce with parallel reception of additional services (e.g. crediting, lending, consultations, information, assistance, purchase by a supplier, supply by a buyer, etc.). 
According to the majority of surveyed farms (80\%) they do not use "interlinked contract for marketing with reception of services from the buyer" and such a special mode has no importance for agrarian sustainability and its aspects (Figure 2). At the same time, a considerable portion of surveyed managers $(17,5 \%)$ evaluates as positive the impact of employed interlinked contracts for marketing with services from a buyer. Those are mostly smaller producers in different subsectors and regions, for which obtained complementary services from the buyers "in package" with the marketing (interest free loan, consultations, inputs supply, laboratory tests, cooling containers, transportation, etc.) are essential. These types of farms do not have own internal capability for organization of such activities and/or easy access, or necessary means for procurement of needed services from the market or other suppliers. The package of received "free" services with marketing of farm produces most frequently includes advance financing, preferential interest and credit, transportation from the farm, agronomic and veterinary consultations, quality and safety laboratory tests, training of personnel, market information, storage and cooling facilities, assistance in finding suppliers or supply of critical inputs (medicaments, forage, etc.), and so forth. Only a tiny portion of the managers asses as negative in regards to agrarian sustainability the utilization of interlinked contract for marketing with additional services from the buyer.

Similarly, to the interlinked marketing, a segment of farms (15\%) also applies "interlinked contracts for inputs supply with reception of services from the supplier", and evaluate that mode as positive for agrarian sustainability (Figure 2). Usually those are producers of different type, subsectors and regions, for which obtained additional services "in package" with the supply are very important. The package of services most often includes: crediting, transportation, consultation, finding a buyer or purchasing of farm produce, etc. The majority of surveyed holdings (85\%) do not practice such form of interlinked supply for not believing the latter is important for agrarian sustainability. Also no manager thinks that such mode of governance of supply negatively affects agrarian sustainability or some of its aspects.

Setting up and/or participation in various collective organizations outside the farms gates (cooperatives, associations, professional initiatives, etc.) considerably facilitates overcoming disadvantages of pure private or market forms for governing of agrarian sustainability. Our survey has found out that the great majority of surveyed farms (85\%) do not take "part in cooperatives" of any type (joint supply, marketing, crediting, logistics, lobbying, etc.) and assess such membership as essential for agrarian sustainability and its individual aspects (Figure 2). Most holdings do not consider as effective the cooperatives membership since they see no significant private benefits but only costs for membership fee, participation in activity, etc. For instance, surveyed cooperative in the South-East region of the country, which used to be a member of the National Union of Agricultural Cooperatives, terminated membership because "there is no benefits and a high cost for membership" (10 stotinki per dka) as well as experienced financial difficulties. Another big producer (and processor) of grape in the same region is a member of a professional association but has "no voice" for protection of its interests.

In the last years the number of traditional cooperatives in Bulgaria substantially decreased and their activity restricted due to the low efficiency, bad management, and losing the comparative advantages in relations to other forms such as own farm, contract, market, firm mode, etc. Many of existing cooperatives started to function as market oriented production cooperatives, and/or in "private" interests of the managers and small groups around them. At the same time, very few coops managed to orient its activity toward better servicing the needs of members and rural communities, as well as for realization of collective projects for socio-economic development, ecology, risk sharing, lobbying, etc. Subsequently, the number of cooperatives, the number of cooperatives members, and the size of cooperative farms considerably decreased in recent years. Therefore, many farmers asses as neutral the impact of cooperatives in achieving the socio-economic and environmental sustainability in the sector. What is more, a small proportion of the managers $(2,5 \%)$ even think that such membership in a cooperative is a negative factor for governing of agrarian sustainability at the contemporary stage. Merely an insignificant portion of farms (12,5\%) participate in some cooperative and evaluate membership as positive for agrarian sustainability or some of its aspects. Those are mainly smaller holdings belonging to farmers in advanced age. For the latter participation in a cooperative gives possibility for (full or part-time) employment and/or cheap and secured supply of essential services and products (e.g. cultivation of farmland, provision of food for household, feed for domestic livestock, mechanization and other services etc.).

In recent years there are also examples for formation of successful "new generation" cooperatives for effective servicing the real needs of members such as collective marketing, processing, negotiating, 
contracting, lobbying for public support, etc. Such instances are not many as membership in that type of cooperatives is small, while participants small producers. The latter further hinders exploring the potential of cooperative form for improving agrarian sustainability even in cases the collective mode outside of the farm gates is strongly needed (collecting negotiation and marketing of output). Many vegetable producers pointed out that the lack of an effective nationwide producers organization is a significant problem. However, such an organization is difficult to establish at the current stage due to the big numbers and conflicting interests of producers, tendency for waiting and "free riding" by nonmember farmers, etc. A big buffalo producer also underlines that the existence of two associations in the country in a situation of small overall number of holdings and animals (total 9000) is a significant problem - inefficiency of activity, division of producers, etc.

The "failure" of collective modes in Bulgarian conditions is also a reason for the low participation of farms in joint initiatives with other agrarian and non-agrarian agents. According to the majority of interviewed managers $(72,5 \%)$ "participation in collective actions with other farmers and non-farmers" do not have significant importance for agrarian sustainability, and practicing by them (Figure 2). For the remaining good portion of holdings however $(27,5 \%)$ participation in diverse collective actions with other farmers and non-farmers is a positive factors contributing for improvement of agrarian sustainability or some of its aspects.

In recent years there have emerged and becoming more and more popular various farmers and nonfarmers informal and formal initiatives ("collective actions") for innovation and quality, revival of rural regions and traditional productions, protection of natural environment, "codes of behaviour", protection of intellectual agrarian property (traditional livestock breeds and crops varieties, special products, specific origins and protected names) etc. Such collective forms are initiated by entrepreneurial farmers, professional organizations, related (processing, trade) industries, non-governmental and civic organizations, etc. These forms are increasingly supported by younger farmers of different type, professional and non-governmental organizations, state and local authorities, and other interested parties. The great potential of and the farmers needs from such "collective" actions however has not been completely explored and the positive effect(s) on agrarian sustainability realized. There are also a few examples of successful collective initiatives for sustainable exploration of natural resources (lands, waters, ecosystem services, etc.) when a great common interests and benefits are present. A good example is the joint actions of one of the surveyed cooperative with other cooperatives and farmers in the South-East region for consolidation of the agricultural lands in areas managed by them.

A partial or complete integration of farms in the vertical (food, supply, etc.) chain is a popular form for improving governance efficiency and the activity of related agents for sustainable development. When market prices and standard ("classical") contracts do not work well the agrarian agents design integrated modes for governing of their relations. Our investigations have found out that only a tiny proportion of surveyed farms $(2,5 \%)$ are involved in some "integration with a supplier of the farm" and evaluate that form as positive in relation to agrarian sustainability (Figure 2). For instance, one of the interviewed livestock operator uses the veterinary and medical services of his retired parents. Such services are critical for successful development of his holding and therefore their supply is internalized ("fully integrated") in the family farm. The predominant part of the surveyed managers (97,5\%) does not believe that integration with a supplier to the farm is important for amelioration of socio-economic and environmental aspects of agrarian sustainability at the current stage of development.

"Integration with a buyer of product" is more widely used form for governing the vertical links in the sector. According to every forth of the interviewed managers they apply some form of integration with a buyer of output and that governance mode favours agrarian sustainability (Figure 2). The partial or complete integration with a buyer (processor, retailer, exporter, etc.) allows a better coordination and control of transactions between partners, guarantee the sale, avoid risk of market prices fluctuation and opportunistic behaviour, and induces strong incentives for joint initiatives, cooperation, and rapid "internal" resolution of emerging disputes in a mutual interest. Such integration mostly is required by the existing strong bilateral or multilateral assets dependency (processing capability, geographical proximity, volumes and timing of delivery, products quality specification, varieties, origin and certification, etc.) of the individual agents in the supply chain. That necessitates (strong incentives, needs, justify additional costs for) elaboration of a special form with designed mechanisms for coordination, stimulation and dispute resolution for facilitation of relations of symmetrically dependent agents. 
In certain cases, the integration with a buyer of farm produce is partial as farms preserve their autonomy, while vertical relations are governed though long-term provision contracts, interlinking purchase with crediting and service supply by buyer, etc. (as it is the case in marketing of raw milk, fresh fruits and vegetables, etc.). In other cases, however, there is a complete integration and control based on a joint (co)ownership or organizational form (firm, holding) as it is the case for most part of the grape for industrial wine production. In such cases, farms either entirely lose their autonomy, or become an internal division of a bigger organizational form, or are registered as separate organizational entities. The latter minimize the risk of joint failure (bankruptcy) of different divisions, tax reduction, increasing public subsidies, and meeting formal requirements for participation in public support programs (restrictions for farm size, ceiling for amount of subsidies, maximum number of project applications, etc.), profiting from established reputation of trademarks and origins and/or keeping "competition" between relatively separated units of the integral form (co-ownership). Our study has also found out a "new" tendency in the evolution of governing structures in certain subsectors of agriculture. The survey proved that a great part of vine-wine complexes in the country are additionally integrated on the base of common ownership in large financial and organizational conglomerates (holdings, groups) in agrarian, and related and unrelated with agriculture sectors.

According to the three quarters of Bulgarian farms they are not vertically integrated with other agents nor they believe that form is essential for agrarian sustainability and any of its aspects. In most cases, there is a situation of competitive markets (many suppliers and many buyers), high standardization and "mass character" of produce, as well as lack of dependencies of partners' assets in the supply chain. In other cases, effective integration of farming with processing, marketing etc. requites certain minimum quantities of product which are difficult to reach. Such example is a surveyed big buffalo grazer whose calculations indicate that it is not profitable to produce in-house (own) buffalo yogurt (selling row milk to another processor without realizing value added). In other instances, specific quality (variety structure, standardization of product) is requited difficult to achieve by smaller producers. In all these cases relationships seller-buyer are more effectively governed through ("faceless") market forms and market price movements (competition), standards contracts for marketing (supply) of product, and/or personal relations (high trust, gentlemen agreements, other sanctioning mechanisms) between counterparts.

To a greatest extent there is a forward vertical integration with buyers of farm produce for Companies $(45,45 \%)$ and Sole Traders $(37,5 \%)$ which assess its positive importance for the governance of agrarian sustainability. Physical Persons are integrated to a lesser degree (13,33\%) while none of the Cooperatives practice that mode. The lack of vertical integration in cooperatives is determined by: "high" specialization in certain "mass" productions (grain and industrial crops) which do not require vertical integration; existence of own processing and/or marketing channels for realization of farm produce; and better (symmetrical) negotiating positions and "power". Degree of vertical integration of agricultural producers increases along with the enlargement of farm size, as the greatest share of integrated with buyers are among the Big holdings (37,5\%), to a lesser extent among Middle size farms $(28,57 \%)$, a little portion among Small producers (20\%), while among Predominately for subsistence holdings there is not such an integration. Greater scales of the agricultural production impose a bigger integration since the market and contractual risk ("failure") is bigger. At the same time, larger buyers (processors, retail chains, etc.) prefer trading with bigger agricultural producers in order to secure needed volumes and decrease transaction costs.

The greatest extent of foreword vertical integration exists in subsectors Permanent crops (60\%), and particularly in grapes for wine production, Pigs, Poultries and Rabbits (50\%), and Grazing livestock $(33,33 \%)$, particularly in milk production. Simultaneously, no holdings specialized in Field crops, Vegetables, Flowers and Mushrooms, and Mix livestock practices integration with buyers and consider it as favourable for agrarian sustainability. Also a relatively small share of farms with Crop-livestock specialization (10\%) and Mix-crops (20\%) develop integration with a buyer and believe it is important for agrarian sustainability. There is a considerable variation in the degree of vertical integration of farms with buyers in different ecological and geographical regions of the country. Comparatively biggest segment of the holdings located in Plain-mountainous regions (every third one) and in South-Central region of the country $(35,29 \%)$ appreciate the positive impact and integrates in marketing of the output. To a least extent are vertically integrated with a buyer the farms located in the Less-favourite mountainous regions $(14,29 \%)$ and South-West region $(12,5 \%)$. 
Various initiatives and pressure of farms suppliers, buyers of farm produce, interests groups and public and large are all important factors for governing of agrarian sustainability in all its aspects. Our study has found out that for all surveyed farms the "initiatives and pressure of suppliers" have no or negative importance in governing of agrarian sustainability and some of its aspects (Figure 2). At the same time, for a relatively good fraction of the surveyed managers $(32,5 \%)$, the "initiatives and pressure of the buyers" of farm produce (processors, traders, exporters, final consumers, etc.) is an essential positive factor for improving agrarian sustainability in all its aspects. The activity of commercial holdings of different type and location is governed by the latter initiatives and pressure. In recent years increasingly are introduced and popularized (advertised) diverse initiatives of retail chains, processors etc. aiming at improving efficiency of Bulgarian farms ("Made in Bulgaria" initiatives), and social and environmental contribution of agricultural production ("green" and "eco" initiatives, corporate "social" responsibility, sustainability movements, organic production, etc.). They all assist, create incentives, and/or pressure on agricultural producers for modernization of activity and increasing different aspects of agrarian sustainability.

Only a tiny proportion of holdings $(2,5 \%)$ evaluates as negative the impact of various initiatives and pressure of buyers on agrarian sustainability. Such external initiatives and pressure for progressive change often augment the costs of farms, diminish competitiveness, and restrict markets for effective marketing of agricultural produce. At the same time, for the majority of Bulgarian farms (65\%) the initiatives and pressure of buyers do not have significant importance and lead to change in agrarian sustainability. At the contemporary stage of development, the main part of the activity of most farms are governed by other important mechanisms and factors ("movements" of market prices, innovations, entrepreneurs initiatives, resource capability, etc.) rather than by the specific initiatives and pressure of the buyers of agricultural produce.

For a comparatively small section of the surveyed farms (15\%) the "initiatives and pressure of the investors" are essential positive factors for improving agrarian sustainability and its different dimensions (Figure 2). That type of (external, hybrid) governance is typical for the bigger and more (vertically) integrated farms, with a significant or entire share of the "external" investors in the ownership of agricultural holding. For instance, when a vine (and wine) complex is integrated in a Holding, they lose (governance, financial, price, etc.) "autonomy", and their relationships with other (internal and external) counterparts are regulated by the common goals of the conglomerate (the "profit" centre/s).

For the majority of farms (80\%) however, the initiatives and pressure of investors have no importance for agrarian sustainability, since these holdings (most often) have no external investors or the outside investors intervene in the farm management. In Bulgaria still there are few agricultural farms with a partial or dominant (co)ownership of external investors. Most holdings are based on individual or family ownership, or a small-group or cooperative membership. Principally, evolution of the corporations with open or close external membership (shares) in agriculture is impeded due to the high uncertainty of production and the enormous costs for outside control on activity (and opportunism) of the managers and farmers. A minor portion of the managers (5\%) evaluate the initiatives and pressure of external investors as negative for the agrarian sustainability. Often involved outside agents (investors) do not have a high competency and/or full information for the specificity of agrarian production and their "active" intervention in the management is considered as negative in regards to agrarian sustainability or some of its aspects.

The initiatives and pressure of different interests groups and public at large are important factors which may direct the governance of agrarian sustainability and its individual aspects in one or another way. According to the half of the surveyed managers the "initiatives and pressure of interests groups and public at large" do not impact considerably agrarian sustainability and some of its dimensions (Figure 2). For every second farm other market, private and public mechanisms for governing of agrarian sustainability are more important than the various initiatives and/or direct pressure of interests groups, local community or large society.

For a relatively small portion of the farms $(12,5 \%)$ the various economic, social, environmental, etc. initiatives of interests groups and public at large and/or certain „pressure "from their side on agricultural producers impact positively agrarian sustainability or some of its aspects. For instance, most often a strong pressure of specific interests groups and/or public at large leads to improvement of eco-management in particular regions, subsectors or type of holdings. According to the good part of the surveyed farms $(37,5 \%)$ the character of existing initiatives and executed pressure of interests groups 
and society impact negatively agrarian sustainability and some of its aspects. There are numerous cases when requirements of strong groups of (business, environmental, etc.) interests or local community are in conflict with sustainable agrarian development on account of other sectors and activity (tourisms, housing construction, industry, natural parks, etc.). There are also reported frequent instances of powerful individuals or groups in or outside agrarian sphere striving to acquire ownership or management rights over significant agrarian resources in certain (high value) ecological and geographical regions. Usually smaller producers are under constant "pressure" to transfer the ownership and/or management of resources against their will and interests. The latter has great negative consequences for agrarian sustainability and some of its aspects. One relatively big surveyed grape producer in order to save his firm from a strong externa take-over pressure (in a combination with a lawsuit for insolvency) leased-out farmland to a "placed person" while court procedures were going on, and simultaneously searched for other "more reliable" ways for salvation.

Generally, different types of farms are affected unequally by the negative influence of the initiatives and pressure of interests groups and community. To a greatest extent from that factor suffer Physical Persons and holdings with Small sizes, out of which $86,67 \%$ and $93,33 \%$ evaluate as negative the importance of initiatives and pressure of interests groups and community for agrarian sustainability. Relatively a smaller portion of the Cooperatives (16,67\%) and farms with Middle sizes $(7,14 \%)$ assess as negative for agrarian sustainability the existing initiatives and pressure of interests groups and society. That "external" factor is determined as negative to a minor extent by the Companies $(9,09 \%)$ and none of the Sole Traders, farms with Big sizes, and Predominantly for subsistence.

As a rule, firms and larger structures have stronger mechanisms for adaptation to external social pressure and/or confrontation to unacceptable pressure of certain interests groups and community. In some cases, certain firms and big farms represent interests of the "special" interests groups aiming at acquiring resources, activity and markets of other agricultural producers. On the other hand, having in mind their miniature size and unimportant resources, the semi-market holdings most often are not subject to external pressure of interests groups and/or community. There is a great variation on the negative impact of the external initiatives and pressure of interests groups and community on agrarian sustainability in different subsectors of agriculture and regions of the country. All farms with Mix croplivestock specialization and every third in Grazing livestock feel the negative impact of the initiatives and pressure of interests groups and community. On the other hand, none of the holdings in Field crops, Vegetables, Flowers, and Mushrooms as well as Pigs, Poultries and Rabbits and Mix livestock assess as negative for agrarian sustainability the existing initiatives and pressure of interests groups and community.

The initiatives and pressure of interests groups and community is a negative factor for all farms located in the Mountainous regions and Less-favoured mountainous regions as well as for a considerable part $(40 \%)$ of the holdings with Lands in protected zones and territories. Simultaneously, the majority of farms in Plain and Plain-mountainous regions evaluate as favourable or neutral for agrarian sustainability the impact of the initiatives and pressure of interests groups and community. The initiatives and pressure of interests groups and community adversely affect the most farms in the SouthWest region of the country (91,07\%), and comparatively minor portion in the South-East $(14,29 \%)$ and South-Central $(11,76 \%)$ regions, and none in the North-Central region.

Cooperation with and an assistance of farms by a business organization or non-governmental organization may contribute to enhancement of agrarian sustainability or some of its aspects. Such an involvement of a "third" party in the governance of agrarian sustainability is necessitated when pure market and private forms do not work, while a state intervention is inefficient or untimely. However, not always such a complex mode of governance of agrarian sustainability produces good results. The majority of interviewed managers (90\%) assess as neutral for agrarian sustainability the "partnership with a business organization", since the latter usually does not exist or it is not essential for the aspects of agrarian sustainability. However, every tenth holding practices some form of partnership with a business organization and believe that such kind ("profit-oriented") partnership with an external organization have a positive impact on agrarian sustainability and some of its dimensions.

Similarly, a great majority of the surveyed farms (90\%) report that "assistance by non-governmental organization" has no significant importance for agrarian sustainability since it either does not exist or the contribution of non-governmental organization toward agrarian sustainability is negligible. What is more, a tiny portion of the managers $(2,5 \%)$ even suggest that "assistance" from the non-governmental 
organization hinders sustainable agrarian development. The latter is a consequence of the inefficient activity of existing non-governmental organizations, or of its content with directions distinct from sustainable development goals. A small proportion of farms $(7,5 \%)$ however implements a beneficial collaboration with some non-governmental organization(s) and evaluates that type ("non-for-profit oriented") assistance as favourable for agrarian sustainability or some of its aspects. For instance, some of the interviewed managers are taken part in a beneficial long-term training in farm management in foreign (German) organizations, while others received (Swiss) support for transition to organic agriculture.

A public intervention in private and market sectors is a necessary and effective means for reaching the objectives of sustainable agrarian development. For example, state subsidizing is one of the main instruments for supporting agricultural producers in the European Union. Different type of subsidies to a various degree favour agrarian sustainability and its individual aspects in different type of farms, subsectors of agriculture, and ecological and geographical regions of the country.

"Farmland area-based state subsidy" is a major component of the Common Agricultural Policy for supporting the income of agricultural producers. According to the majority of surveyed managers $(57,5 \%)$ that type of subsidies impact positively agrarian sustainability and all its dimensions (Figure 2). That mode of public assistance aims at increasing economic and social sustainability of agriculture and rural regions and overcoming disproportions with other sectors of economy. Along with this, reception of a single area-based payment is also related with an obligation for maintaining the land in a good agronomic condition by landowners and farmers, which improves environmental sustainability.

Nevertheless, a good portion of the farms $(27,5 \%)$ evaluates as neutral the effect of state subsidies for utilized agricultural land in regards to agrarian sustainability and its individual aspects. Expected effect of this public instrument on agrarian sustainability for many leasing-in farmland holdings is minimized or annulled due to the fact that many owners of lands augment rent with a part (or the entire) amount of eligible subsidies. Some farms and landowners lease out "for free" to other farmers without registering the deal and receiving entire due subsidies for owned land. In all these cases the public subsidies for utilized agricultural land are actuary taken not by the farmers operating the land but external agents (farms, landlords, middlemen, etc.). Moreover, $15 \%$ of the managers believe that this type of subsidies is a negative factor for agrarian sustainability. The good part of the farmland area based payments in the country is received by a relatively small proportion of (large) agricultural holdings and in certain subsectors of agriculture (grain, oilseeds, etc.). The latter further contribute to income disparity of different type of farms, subsectors, and regions of the country.

Favourable impact of the state farmland area based subsidies to a various extent affects positively the farms of different juridical type, size, production specialization, and ecological and geographical location. Our study has found out that to a greatest degree the positive impact of area-based subsidizing is felt by the Cooperatives (100\%), Companies (54,55\%), and Physical Persons (53,33\%). Furthermore, with increasing the size of agricultural holdings also progressively grows the favourable impact of that type of public support. While in holdings Predominately for subsistence merely a third assess as positive that type of EU support, among the farms with Big sizes whose share is three quarters.

There are also variations in the positive impact of the state area-based subsidies in different subsectors of agriculture. From this instrument of public support to a greatest extent take advantage farms specialized in Mix-livestock (100\%) and Field crops (80\%). Among producers specialized in Permanent crops and Vegetables, Flowers, and Mushrooms every other assesses as positive the received area-based subsidies in relation to agrarian sustainability. In holdings specialized in Pigs, Poultries and Rabbits none of the surveyed managers indicates that this type of public support favours agrarian sustainability. There is also a considerable differentiation in the positive effect of the state land-based subsidies in different ecosystems and regions of the country. Comparatively the biggest proportion of farms in the Plain-mountainous regions (80\%) and Less-favoured mountainous regions $(57,14 \%)$ evaluate as favourable the impact of utilized farmland based subsidies on agrarian sustainability and its individual aspects. At the same time, merely a quarter of the holdings in Less-favoured nonmountainous regions take advantage of that type of public support. To the greatest extent the positive impact of area-based subsidies is felt by the farms in North-Central region (80\%) and South-East region $(71,3 \%)$ of the country, while in the South-West region a smallest degree of holdings benefited $(41,07 \%)$.

Another main form of public support is the national (top-ups) subsidizing for particular activities and products. Utilized agricultural land based subsidizing creates great differences in the incomes and 
effectiveness of individual subsectors and producers, which necessitates "correction" though direct subsidizing the production of certain products, grazing livestock, executed (restricted) activities, etc. According to the majority of interviewed managers (57,5\%) "state subsidies for activities and products" does not affect significantly agrarian sustainability (Figure 2). Simultaneously, none of the surveyed believes that such type of direct support to production is a negative factor for agrarian sustainability and any of its aspects. For a good portion of the surveyed farms (42,5\%) state subsidizing for activities and products is a positive factor for maintaining and improving agrarian sustainability or some of its elements.

There is a great variation in the degree of the public subsidizing of production among different type of farms. The biggest share of holding assessing as positive the impact of direct subsidies for products and activities is in the group of Physical Persons (60\%). On the other hand, only a quarter of the Sole Traders feel the favourable effect of that type public support. The extent of the subsidizing for products and activities augments along with the farm size. Among the biggest operators every other one take advantage from the positive effect of these subsidies, while among semi-market farms only a third. That form of public support to the greatest extent participate and take advantage farms in Mix-livestock (all), Mix crop-livestock specialization (70\%), and in Grazing livestock (two-third). On the other hand, that mode of state support reaches none of the farms in Pigs, Poultries, and Rabbits, and only one-fifth of holdings in Field crops and Mix crops as evaluate it as positive for agrarian sustainability.

In different type of ecosystems that form of governing of sustainability to a greatest extent is implemented by the farms in Mountainous regions (two-third) and Less-favoured non-mountainous regions (three quarters) and relatedly lesser degree by the holdings in Plain-mountainous regions (a third). A relatively bigger faction of the farms in South-West region $(51,78 \%)$ is benefited from that form of public support in comparison with the rest three regions where the schemes cover around $40-43 \%$ of the holdings.

The failure of effective market and private investments in agrarian sectors is a reason for the state intervention in supply of a preferential credit and subsidies for long-term ("capital") investments for improving sustainability. A half of the interviewed farms used "state subsidizing for new investments" and evaluate that form of public support as positive in relation to agrarian sustainability and its main aspects (Figure 2). The rest half of the holdings however, have not benefited from that mode of public support and asses it as neutral in regards to agrarian sustainability. Many instances are pointed out when public investment funds are utilized ineffectively due to the high amount of subsidies. For example, permanent crops (walnuts, rosehips, alfalfa, etc.) have been created without harvesting the yields or assets destroyed once the monitoring period (a "pay-back" business plan) before the authority is expired.

Firms of different type to the greatest extent participated in diverse schemes for state subsidizing of new investments - Companies $(81,82 \%)$ and Sole Traders (50\%). The largest portion of supported by that public support instrument farms are among the groups of the Big size $(87,5 \%)$ and Middle size $(64,29 \%)$, as well as specialized in the Permanent crops (90\%), Mix livestock (100\%), and Grazing livestock (66,67\%). Simultaneously, none of the holdings Predominately for subsistence and from the sector Vegetables, Flowers and Mushrooms is favoured by that mode of governance of agrarian sustainability.

A greater proportion of holdings located in the Plain $(56,25 \%)$ and Plain-mountainous $(53,33 \%)$ regions are beneficiaries of the public investment subsidies in comparison with the farms with Lands in protected zones and territories (20\%) and Mountainous regions (33,33\%). A good share of the farms in South-East region (85\%) and North-Central region (60\%) benefit of the positive impact of that form of public intervention comparing to the holdings in the South-West $(39,28 \%)$ and South-Central $(41,18 \%)$ regions of the country.

The green payments and environmental measures of the Program for Rural Development (PRD) are another instrument for public support to sustainable agrarian development, particularly its environmental aspect. The greatest proportion of surveyed managers $(42,5)$ assesses "green payments and eco-measures of the Program for Rural Development" as positive for agrarian sustainability (Figure 2). Public subsidies of that type are considered as mode of payment for services (public goods provision) and compensation of the costs of farmers for carrying out of an important social function - care for natural resources. For their part, the farms participating in that hybrid form of governance are obliged to implement certain ("good") practices for conservation and improvement pf lands, waters, landscape, natural biodiversity, etc. It is indicative that none of the interviewed farms thinks that type of public 
support has a negative impact on agrarian sustainability, and particularly on its environmental aspect. Nevertheless, according to the majority of holdings $(57,5 \%)$ that form of public support has no significant importance for agrarian sustainability and any of its aspects. That is consequence of the fact that most farmers either do not receive such a support, or its form and amount affect anyway agrarian sustainability and its different aspects.

To the greatest extent the positive impact of green payments and other eco-measures of the PRD benefit the Cooperatives (83,33\%) and Companies (63,64\%), farms with Big sizes (75\%), and those specialized in Mix livestock (100\%), Field crops (60\%), and Permanent crops (50\%). The favourable impact of the public payments for environmentally friendly agriculture are mostly felt by the holdings in the Less-Favoured mountainous regions $(57,14 \%)$ and Plain-mountainous regions $\left(46,67^{\circ} \%\right)$, as well as those located in the South-East region of the country $(57,14 \%)$. On the other hand, this instrument of public support is a positive factor for agrarian sustainability for a relatively small portion of the holdings in the Less-favoured non-mountainous regions (25\%), North-Central (20\%) and South-West $(22,93 \%)$ regions of the country.

Various forms of public support to farmers organizations of different type are a major component of the public intervention in agriculture and mode for increasing agrarian sustainability. That type of public support is extremely important for Bulgarian agriculture where evolution of the effective organizations of agricultural producers for correction of market and private failures considerably lag behind the needs of farmers. For predominant part of the interviewed managers (95\%) existing at the contemporary stage of development in the country "state support to farmers organizations" does not assist in any way agrarian sustainability (Figure 2). Apparently envisaged instruments of the state intervention in that exceptionally important area are not used by the farmers and/or lead to actual improvement of the governance of agrarian sustainability in the country. For the rest tiny portion of the holdings $(5 \%)$ the state forms for supporting farmers organizations are a positive factor for improving sustainability in the sector or some of its main aspects (social, economic, environmental).

In Bulgarian agriculture there also applied some other measures of the Program for Agrarian and Rural Development aiming at supporting the actions of agrarian agents for improving different aspects of agrarian sustainability. According to the great part of the surveyed managers (72,5\%) "other measures of the Program for Agrarian and Rural Development" do not impact significantly the level of agrarian sustainability (Figure 2). That is subsequent of the fact that considerable number of the Bulgarian farmers either does not have practically access to that form of public support or see that intervention as an essential factor for agrarian sustainability or some of its dimensions. The rest smaller portion of the farms $(27,5 \%)$ have taken and/or are taking part in other measures of the PRD, and evaluate them as positive for agrarian sustainability or some of its aspects.

To a greatest extent the favourable impact of other measures of the PRD is pointed out by Companies (45,45\%), holdings with Big size (50\%), farms specializes in Permanent crops (60\%), and located in Plain-mountainous regions (46,67\%), and North-Central region of the country (80\%). For the best portion of the farms in the rest groups of juridical type, sizes, product specialization, ecological and geographical situation, the favourable impact of that form of public support is relatively small or absent.

As far as the remaining public programs are concerned, according to the greatest part of the interviewed managers (95\%) they do not contribute in any way for agrarian sustainability (Figure 2). The rest mall portion of the holdings $(5 \%)$ are taking or have taken part in some other type public (state, sectoral, social, environmental, regional, international, etc.) support and development program, and they believe that involvement favour agrarian sustainability or some of its main aspects.

Norms for good agricultural practices and cross compliance aim at directing actions of the agricultural producers toward achieving sustainable agriculture in its three aspects - social, economic and ecological. Most surveyed managers (65\%) indicate that "requirements for cross compliance and good agricultural practices" do not have substantial importance for the governance of agrarian sustainability. Many agricultural producers do not comply fully (or at all) with compulsory norms and systems of good agricultural practices, or they appreciate that such official standards contribute to agrarian sustainability. What is more, one tenth of the farms points out that mandatory requirements for cross compliance and good agricultural practice have a negative effect in regards to agrarian sustainability or some of its aspects. The latter is often due to the fact that superior "external" standards increase costs of producers (diminishing economic sustainability) without being associated with an expected positive impact on overall sustainability. In some cases, such norms do not correspond to the specific conditions 
of each holding and contribute to accomplishment of desired objectives for sustainable development of related farms, subsectors, ecosystems or geographical regions.

According to every forth of the surveyed managers the requirements for cross compliance and good agricultural practices are positive factor for improving agrarian sustainability and particularly its social and environmental aspects. The favourable impact of that mode of public intervention is reported in equal extent by farms of different juridical kind, sizes, production specialization, and ecological and geographical location. The formal norms for good agricultural practices and obligatory requirements for cross compliance assist agricultural producers and impose a "type of behaviour" leading to improvement of agrarian sustainability at farm, sectoral and regional levels.

Different forms of local support by the community and/or local authority are means for supporting market, private, collective and state modes, and for correction of market, private and/or state failure(s) and improvement of agrarian sustainability in the region. According to the predominant portion of the interviewed managers (95\%) "existing public support in the region" has no significant importance for agrarian sustainability and its diverse aspects (Figure 2). In many cases such support practically is missing or it is insufficient, unsustainable, or not well designed in the interest of agrarian development in the region. An interviewed big agricultural producer describes public support in the region "only as moral". The remaining very small portion of the surveyed holdings (5\%) evaluates as a positive the existing public support in the region in regards to sustainable agrarian development. There is tinny number of good examples where the local authority and/or public organization assist directly or indirectly farmers, farm households and organizations with appropriate policies, initiatives (festivals, product promotions, etc.), information, (co)financing, partnership and join forms, lobbying before superior authorities etc., and that intervention improves sustainability of agriculture at farm, (sub)sectoral, ecosystem and/or regional level.

Formal and informal voluntary standards, norms and rules, introduced and applied by the farmers and/or farmers organizations are new developing form for governing of agrarian sustainability. They are expression of the willingness of individuals or a group of producers to impose voluntary quality, social, ecological etc. standards, norms, rules and/or restrictions for sustainable agriculture overpassing the official norms. According to the majority of surveyed holdings $(72,5 \%)$ they do not apply any "voluntary standards, norms and rules" and consider that modes as important for agrarian sustainability and some of its aspects (Figure 2). A small portion of the managers $(2,5 \%)$ however, indicates that "voluntary" standards, norms and rules, which are required ("imposed") by the professional organizations, big buyers, consumers associations, interests groups, governmental agencies, etc. increase operational costs (for studying, introduction, implementation, controlling, disputing, etc.) and affect negatively agrarian sustainability. Every forth of surveyed managers assess as positive for agrarian sustainability implementation of (participation in initiatives for) voluntary standards, norms, and rules. Those are innovative farms from different juridical type, size, product specialization, ecological and geographical location, which implement such emerging private or collective mode for governing of agrarian sustainability (or some of its aspects).

Provision of free services like training, advices, etc. by the state is an important form for public support to agrarian sector. Every fifth of the interviewed managers reports of using in the past or presently some form of "provided by the state free services (training, advices, etc.)", and assess that mode of state assistance as a positive factor for agrarian sustainability and its dimensions (Figure 2). In recent years there have been carried out numerous trainings and consultations by the Agricultural Advisory Service and other government organizations, aiming at improving qualification and awareness of agricultural producers. In this mode smaller size holdings are mostly involved, which do not have or cannot afford to hire experts in management, finance, agronomy, etc. and rely on free state services in the area. At the same time however, the majority of the farms do not believe that provision of free services (training, advices, etc.) by the state is essential for agrarian sustainability. The latter confirms that the majority of Bulgarian farms have no access or use free state services, or evaluate the importance of (received) services as neutral in relation to agrarian sustainability and its individual aspects. What is more, a small fraction of the managers $(7,5 \%)$ indicates that "assistance" of the farms by the state through free services as training, advices etc. is a negative factor for agrarian sustainability. According to a portion of the users of the state system of free farm services it does not work well and impedes achievement of agrarian sustainability due to inefficiency, high related costs for farmers, inadequate information, improper training, etc. 
Another form for public (government) involvement in the private and collective sector for governing of agrarian sustainability is a public-private partnership. The majority of the surveyed managers (90\%) do not report participating in a "partnership with community, state, international etc. organization", nor evaluate that hybrid mode as important for agrarian sustainability (Figure 2). The latter is subsequence of the fact that in the country still there are not popular and widespread formal partnership forms of agricultural producers with a community, state and/or integrational organization. The rest small portion of the holdings $(10 \%)$ however, applies some partnership with a community, state and/or international organization, and evaluates it as positive for agrarian sustainability and its main aspects. In the agrarian sector in the country there are few examples for successful partnerships of individual farmers or farmers organizations with local, national or international public organizations, aiming at implementation of certain social, environmental, regional, etc. programs, introduction of new initiatives, standards, supporting and training young entrepreneurs and innovators, association of producers and interested parties, etc.

Tax preferences of different type are popular public form for supporting certain producers, subsectors, regions, etc. The majority of surveyed holdings $(77,5 \%)$ does not use "tax preferences" and/or suggest that mode is important for agrarian sustainability and its dimensions (Figure 2). An insignificant proportion of the interviewed managers $(2,5 \%)$ estimates that tax preferences for certain activities, productions, regions, etc. are even a negative factor for the agrarian sustainability. Every fifth of the managers however, assess as positive received by tax preferences in regards to agrarian sustainability, mostly for its economic aspect. The surveys farm most often underlines the favourable impact of returned excise for diesel fuel, the zero excise duty for wine etc. Beneficiaries of that type of public support are predominately bigger producers of different type in crop subsectors of agriculture (with enormous costs for purchasing fuel, mechanization, and transportation), and integrated farms in the vine-wine sector.

Mandatory social security payments are an important form for public intervention aiming at improving the social position of the workers in the sector and elevating agrarian sustainability. According to $15 \%$ of the surveyed managers they strictly implement "obligatory social security payments" and believe that instrument favour agrarian sustainability, particularly its social aspect (Figure 2). Those are mostly larger cooperative and other farms, for which the social security payment of workers is a priority and evaluated as a positive factor for improving of overall efficiency. The latter type of farms is also the mostly controlled by the authorities for complying with the social security payment norms, they often strictly implement formal regulations, and perceive that mode as a part of the normal farm practice.

At the same time, a good portion of the holdings (17,5\%) assess as negative compulsory social security payment in relation to agrarian sustainability, and particularly for its economic aspect. These are larger farms, hiring many permanent and seasonal labours, for which the social payments take a big share in the total costs. The enhanced control and sanctions from the government agencies on big farms give lower possibility to ignore regulatory requirements in the area. A good number of managers are also complaining that they are forced to hire many "unmotivated and unskilled workers", for which they pay social securities without getting corresponding labour contribution (high costs for negotiation, training, unjustified absences from work, low working discipline, high job turnover, etc.). For the latter type of holdings, the mandatory social security payments are a significant additional cost which is not associated with relevant positive effects on agrarian sustainability.

The mandatory insurance is one of the forms of public intervention in the risk governance in agrarian sphere and for enhancement of agrarian sustainability. In agriculture, pure market forms for insuring against risk are not popular due to the lack of appropriate insurance coverages (products), high costs (premiums), frequent disputes over claims for compensation for damages, lack of tradition, etc. In many instances, the market forms are not applied due to the employment of other more effective private modes of risk management. Usually, compulsory assurance is requited for participation in some of the public support measures as it is necessary to insure permanent crops and buildings, livestock, yields, labour, etc. in projects for modernization of agricultural holdings. One fifth of the surveyed farms point out the favourable impact of "mandatory assurance" on agrarian sustainability and its aspects. Those are mainly bigger farms, which take part in different forms of public support programs requiring obligatory insurance (Figure 2). 
According to a good part of the managers $(17,5 \%)$ however, the mandatory insurance has negative consequences for agrarian sustainability, because it increases the production costs and claims for damages are associated with multiple problems. Moreover, for a major part of the holdings $(62,5 \%)$ the obligatory assurance has no importance in regards to agrarian sustainability or some of its aspects. The majority of Bulgarian farms either does not practice that mode of (market) assurance or see any benefits from that form for governing of agrarian sustainability.

Social recognition of the contribution of the farmer, the owner and/or the manager of the holding is an important factor for stimulating (improving) the actions for achieving agrarian sustainability. According to a large part of the interviewed managers $(37,5 \%)$ "social recognition of their contribution" is an essential regulating behaviour and directing activity positive factor for improving agrarian sustainability (Figure 2). The great importance of the "social image" of the farmer and the recognition by the community in the region and country is pointed out by the innovating entrepreneurs and farmers of different kind, size, production specialization, ecological and geographical regions. That informal form of social governance of the behaviour is particularly typical for agriculture, where farmers, their activities and "reputation" are well known by the professional community, related sectors and general community in a residential area, region or country. For the remaining larger portion of the holdings $(62,5 \%)$ however, social recognition of the farmer's contribution has no importance for agrarian sustainability and its dimensions.

Informal contracts between agricultural producers, farmers and suppliers, farmers and buyers, etc. are widely used in agrarian sphere. Unlike written contracts, having a legitimate power and being able to be disputed though a court system, informal agreements are governed solely by the "good will" and trust between counterparts and unwillingness to lose cooperation with a partner and/or social reputation. The greatest part of surveyed managers $(60 \%)$ indicates the positive importance of the "informal agreements" in relation to the governance of agrarian sustainability (Figure 2). A significant fraction of the relationships in the agrarian sphere in the country are still governed (more) effectively through that traditional mode between counterparts, knowing each other well and frequently trading. For a good proportion of the holdings $(30 \%)$ informal agreements have no importance for agrarian sustainability. Increasingly the relationships between counterparts are governed though a formal contract since they cover rare deals, large volumes, unknown counterparts, big partners (retail chains, processors, electricity, water, etc. suppliers) and other organizations (banks, insurance companies, state agencies), for which "formal" written contracts are mandatory. Besides, existence of formal contracts (e.g. for marketing of output) very often is a precondition for application for a bank loan and some of public support programs.

Nevertheless, each tenth of the holdings believes that informal agreements in the sector impact negatively agrarian sustainability and its components. For that form is too expensive or impossible to resolve conflicts between parties in case negotiated obligations are not fulfilled or conditions of exchange change (sharp increase in prices of purchased by farm inputs or considerable decline in market prices of farm produce). Interviewed farmers have given many examples, in which they are cheated and realized huge damages due to nonfulfillment of certain informal agreements by the partners, without been able to enforce their rights in court (as a result of difficulties, failure, more favourable opportunities for deals, etc.). Moreover, widely used informal agreements in the country are associated with development of a huge informal (grey) sector in agriculture, with unenforced quality, safety and environmental standards, unpaid taxes and social securities, juridical consultations fees, costs for contracts preparation, writing and registration, etc. All these increase production costs in the "light" sector of agriculture, and inferior competitiveness and efficiency comparing to the informal sector. Therefore, farms complying with the formal rules assess as negative for agrarian sustainability widespread application of informal agreements.

Different type of holdings, subsectors and regions apply unevenly the informal agreements and evaluate as positive their role for agrarian sustainability. To the greatest extent informal agreements dominate among Physical Persons (73,33\%) and firms of various kind - Sole Traders $(62,5 \%)$ and Companies $(63,64 \%)$. Simultaneously, relatively a small portion of the cooperative farms $(16,67 \%)$ applies that mode for governing relations with divers agents, and assess it as positive for agrarian sustainability.

The smallest semi-market holdings entirely govern their relationships with other agents through informal agreements. At the same time, farms with Middle sizes to the least extent (50\%) use contract of the latter type. Informal agreements are most popular in subsectors Mix livestock (100\%), Permanent crops and Mix crop-livestock (by 80\%). Farms applying at least informal agreements and assessing them 
positively are among Field crops (20\%) and in Vegetables, Flowers, and Mushrooms (25\%). Informal contracts to the biggest degree are employed by the holdings in Mountainous regions $(88,89 \%)$, while in the Plain regions to smallest extent. The South-West region of the country is the leader in terms of the proportion of farms $(73,21 \%)$ practicing informal agreements, while fewer number of farms in the SouthEast region $(42,86 \%)$ evaluate as positive that type of governance of relations. The structure and the scope of informal agreements in different type of farms, subsectors of agriculture, type of ecosystems and regions of the country give also some tentative insight for the evolution of the informal sector in agrarian sphere at the present time.

Identification of the links (correlation) between the level of agrarian sustainability in individual farms and the importance (efficient, "positive" impact) of diverse private, contractual, collective and hybrid modes of governance for these holdings, allows to determine the real efficiency of the specific governing modes for improving agrarian sustainability in the country. For most of implemented governing forms there exist a strong correlation between the positive estimates of the managers for the impacts on agrarian sustainability, and the archived good (and high) level of agrarian sustainability in the corresponding farms (Figure 3).

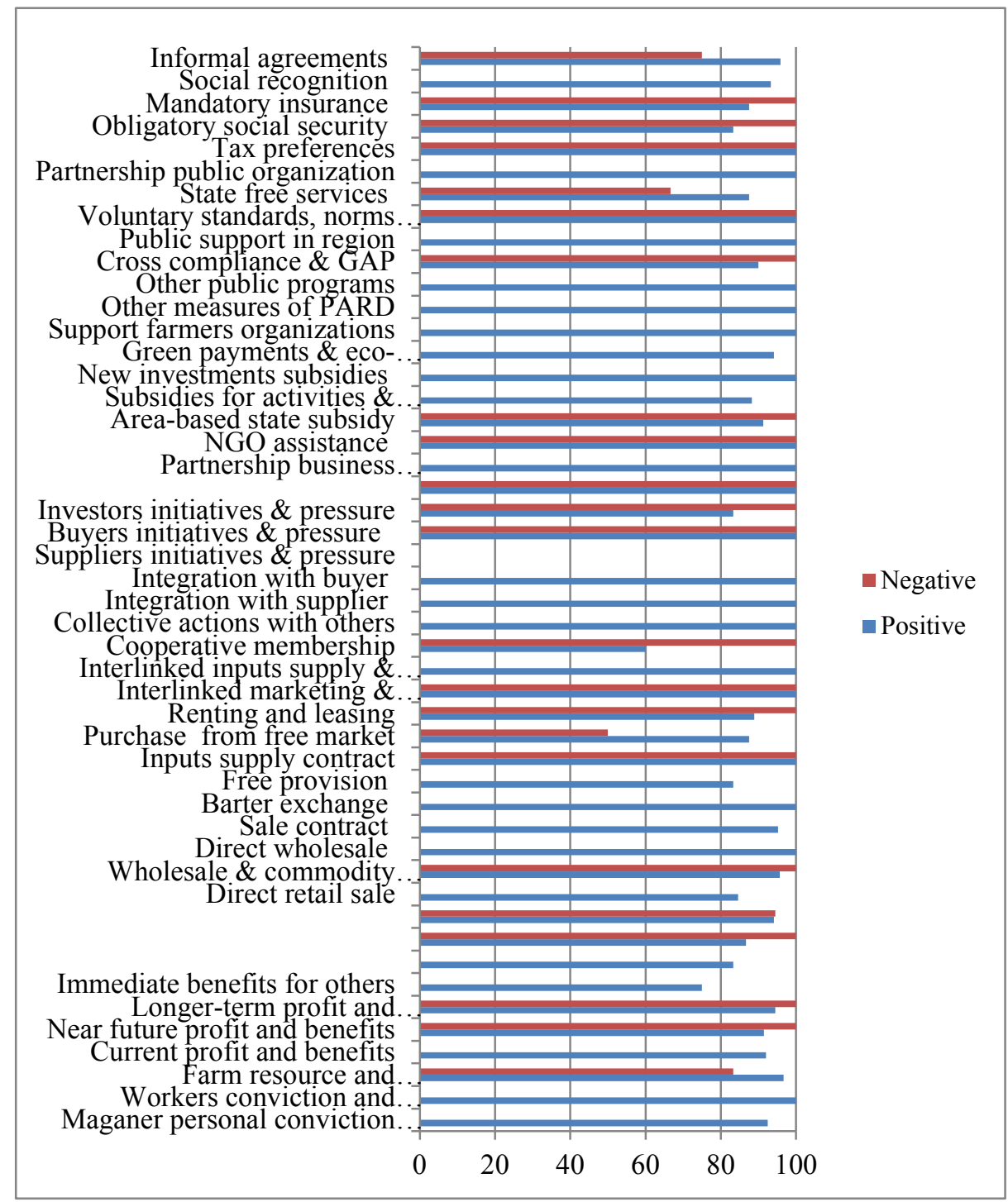

Source: interviews with managers of farms, 2017, author calculation

Figure 3. Share of farms with good and high sustainability evaluating as positive or negative the impact of individual governing forms on agrarian sustainability in Bulgaria (percent) 
Thus, preferred and employed by the farms governing forms are critical and (most likely) their choice by the managers to a certain extent actually contribute to achievement of a higher agrarian sustainability in surveyed holdings. Effectiveness of individual governing modes is as following: personal conviction and initiatives of the farmer $(92,5 \%)$, personal conviction and initiatives of workers $(100 \%)$, profit and benefits in the present time (92\%), immediate benefits for other persons and groups $(75 \%)$, diversification of activity in the farm (83,33\%), direct retail sells of products and services $(84,62 \%)$, sale on wholesale and commodity markets (100\%), marketing contract for products and services $(95,24 \%)$, barter exchange of products and services (100\%), free provision of resources, products, services and activities (83,33\%), interlinked supply contract with services by the supplier (100\%), participation in joint actions with other farmers and non-farmers (100\%), integration with the buyer of produce (100\%), partnership with a business organization (100\%), state subsidies for activities and products $(88,24 \%)$, state subsidies for new investments (100\%), green payments and eco-measures of the PRD $(94,12 \%)$, state support to farmers organizations (100\%), other measure of the PARD (100\%), participation in other public programs (100\%), existing public support in the region (100\%), partnership with community, state, and integrational organization (100\%), and social recognition of the contribution $(93,33 \%)$.

For the rest of analysed governing forms used by the surveyed farms there is no clear relation between the superior levels of agrarian sustainability and the managers assessments on sustainability impact of a particular mode. In all these cases, preferred by the managers governing forms do not lead to expected results (due to novelty, a short period of implementation, inefficiency in terms of sustainability), or manifested "joint (cumulative, complementary, contradictory) effect" with other employed governing modes. It is also likely that the managers' estimates are not precise and represent the impact of a particular governance form on farm private efficiency rather than the real impact on agrarian sustainability (overall social efficiency).

\section{Conclusion}

Our empirical study has just been a first attempt to identify the complex links between the governing forms employed by the Bulgarian farms and the level of agrarian sustainability in the country. It made it possible to identify the mechanisms and modes of governance mostly used by the agricultural producers, and assess their impact on agrarian sustainability as a whole, and in different subsectors, geographical and administrative regions, (agro)ecosystems, and type of farming enterprises. We have found out that in the specific socio-economic, institutional and natural environment agricultural producers of different juridical type, size, specialization, and location use quite unlike mixture of effective market, private, collective and hybrid modes for governance or their activities and relations. Individual factors and modes which mostly contribute to improvement of agrarian sustainability at the current stage of development in the country are: managers' personal convictions and initiatives, farms resources and innovation potential, near future profit and benefits strategies, market prices levels and dynamics, area-based EU subsidies, and informal agreements.

Nevertheless, evolution of the system of agrarian governance and the level of agrarian sustainability depends on various economic, political, behavioural, demographic, technological, international, natural etc. factors. Individual, joint and spill over effects of all these factors are to be accounted for and assessed in further research in that new area. Particularly, it is important to incorporate into analysis and assess the impact of the formal and informal components of institutional environment which are critical and eventually determine agents' behaviour and level of agrarian sustainability. Besides, always there is a certain "time lag" between the "improvement" of the system of governance, and the positive, negative or neutral impact on agrarian sustainability, and its economic, social and environmental aspects. All these factors are to be studied in such assessments as estimates also made on the "dynamics" of the impact over a longer time horizon.

Research on the relations between the governing structure and the (level and dynamics of) agrarian sustainability is to continue though expansion of the number and representation of surveyed holdings, and the spectrum of the specific governing modes used by the farms of different type as well as assessments of the impact of institutions on agrarian sustainability. What is more, applied methods are to be enriched in order to specify better the complex relations between the agrarian governance and 
sustainability. Furthermore, modes of governance at higher hierarchical levels (sector, national, transnational) have to be specified and their separate and/or complementary impact on agrarian sustainability evaluated.

Having in mind the importance of comprehensive assessments of the impacts of governing system on agrarian sustainability, and the enormous benefits for farm management and agrarian policies, this type of studies are to be expanded and their precision and representation are to be increased. The latter however, requires a close cooperation between all interested parties, and participation of farmers, agrarian organizations, local and central authorities, interest groups, research institutes and experts, etc. Moreover, the precision of estimates has to be improved, and besides on the estimates of farm managers to incorporate other relevant information - experts and stakeholders' assessments, monitoring, report, statistical, etc. data, studies on "actual" (rather than declared) behaviour of various agrarian and nonagrarian agents, and associated "effects" on agrarian sustainability, etc.

\section{References}

1. H. Bachev, Governance of Agrarian Sustainability, New York: Nova Science Publishers, 2010.

2. H. Bachev, Management of Farm Contracts and Competitiveness, VDM Verlag Dr.Muller, 2010.

3. H. Bachev, "Defining and Assessing the Governance of Agrarian Sustainability", Journal of Advanced Research in Law and Economics, Volume VII, Issue 4(18), 797-816, 2016.

4. H. Bachev, The Sustainability of Farming Enterprises in Bulgaria, Cambridge Scholars Publishing, 2018.

5. H. Bachev, B.Ivanov, D.Toteva, E.Sokolova, "Agrarian Sustainability and its Governance - Understanding, Evaluation, Improvement", Journal of Environmental Management and Tourism, Vol. 7, issue 4 (16), 639-663, 2016.

6. EC, Sustainable agriculture and rural development policy - agricultural development, European Commission, 2017.

7. E. Furuboth and R. Richter, Institutions and Economic Theory: The Contribution of the New Institutional Economics. Ann Arbor: The University of Michigan Press, 1998.

8. M. Georgiev, "Rent Seeking" in Agricultural Contracts in the Country, Trakia Journal of Sciences, Vol. 8, 3, 230-233, 2010.

9. D. North, Institutions, Institutional Change and Economic Performance, Cambridge: Cambridge University Press, 1990.

10. S.Raman, Agricultural Sustainability. Principles, Processes and Prospect., New York: The Haworth Press Inc., 2006.

11. X. Sauvenier., J. Valekx, N. Van Cauwenbergh, E. Wauters, H.Bachev. K.Biala, C. Bielders, V. Brouckaert, V. Garcia-Cidad, S. Goyens, M.Hermy, E. Mathijs, B.Muys, M.Vanclooster. and A.Peeters, Framework for Assessing Sustainability Levels in Belgium Agricultural Systems - SAFE, Belgium Science Policy, Brussels, 2005.

12. D.Terziev and, D. Radeva, Studying the New Agriculture. 2nd International Conference on Development and Economics (I.CO.D.ECON.), Thessaloniki, Greece, Conference proceedings.

Available: https://icodecon.com/images/docs/proceedings_2017_3_18.pdf, 175-179, 2016.

13. UN, Report of the United Nations Conference on Environment and Development, 3-14 June 1992, Rio de Janeiro: United Nation, 1992.

14. UN, Paris Climate Change Conference - November-December 2015.

15. O. Williamson, The Mechanisms of Governance. Oxford University Press, 1996. 